\title{
Mars Extant Life: What's Next? Conference Report
}

\author{
Conference leads: B.L. Carrier, ${ }^{1}$ D.W. Beaty, ${ }^{1}$ M.A. Meyer, ${ }^{2}$ Sub-Team leads: J.G. Blank, ${ }^{3,4}$ L. Chou, ${ }^{5,6}$
}

S. DasSarma, ${ }^{7}$ D.J. Des Marais, ${ }^{3}$ J.L. Eigenbrode, ${ }^{6}$ N. Grefenstette, ${ }^{8}$ N.L. Lanza, ${ }^{9}$ A.C. Schuerger, ${ }^{10}$

P. Schwendner, ${ }^{10}$ H.D. Smith, ${ }^{3}$ C.R. Stoker, ${ }^{3}$ J.D. Tarnas, ${ }^{11}$ K.D. Webster, ${ }^{12}$ and Sub-Team contributors:

C. Bakermans, ${ }^{13}$ B.K. Baxter, ${ }^{14}$ M.S. Bell, ${ }^{15}$ S.A. Benner ${ }^{16}{ }^{1}$ H.H. Bolivar Torres, ${ }^{17}$ P.J. Boston, ${ }^{18}$ R. Bruner, ${ }^{19}$

B.C. Clark, ${ }^{20}$ P. DasSarma, ${ }^{7}$ A.E. Engelhart, ${ }^{21}$ Z.E. Gallegos, ${ }^{22}$ Z.K. Garvin, ${ }^{23}$ P.J. Gasda, ${ }^{9}$ J.H. Green, ${ }^{24}$

R.L. Harris, ${ }^{23}$ M.E. Hoffman, ${ }^{22}$ T. Kieft, ${ }^{25}$ A.H.D. Koeppel, ${ }^{26}$ P.A. Lee, ${ }^{27}$ X. Li ${ }^{28}$ K.L. Lynch, ${ }^{29}$ R. Mackelprang, ${ }^{30}$

P.R. Mahaffy, ${ }^{6}$ L.H. Matthies, ${ }^{1}$ M.A. Nellessen, ${ }^{22}$ H.E. Newsom, ${ }^{22}$ D.E. Northup, ${ }^{22}$ B.R.W. O'Connor, ${ }^{31}$

S.M. Perl, ${ }^{1}$ R.C. Quinn, ${ }^{3}$ L.A. Rowe, ${ }^{32}$ B. Sauterey, ${ }^{33}$ M.A. Schneegurt, ${ }^{34}$ D. Schulze-Makuch, ${ }^{35}$

L.A. Scuderi, ${ }^{22}$ M.N. Spilde, ${ }^{22}$ V. Stamenković, ${ }^{1}$ J.A. Torres Celis, ${ }^{17}$ D. Viola, ${ }^{3}$ B.D. Wade, ${ }^{36}$

C.J. Walker, ${ }^{37}$ R.C. Wiens, ${ }^{9}$ A.J. Williams, ${ }^{38}$ J.M. Williams, ${ }^{22}$ and J. $\mathrm{Xu}^{39}$

\footnotetext{
${ }^{1}$ Jet Propulsion Laboratory, California Institute of Technology, Pasadena, California, USA.

${ }^{2}$ NASA Headquarters, Washington, DC, USA.

${ }^{3}$ NASA Ames Research Center, Moffett Field, California, USA

${ }^{4}$ Blue Marble Space Institute of Science, Seattle, Washington, USA.

${ }^{5}$ Georgetown University, Washington, DC, USA.

${ }^{6}$ NASA Goddard Space Flight Center, Greenbelt, Maryland, USA.

${ }^{7}$ Department of Microbiology and Immunology, Institute of Marine and Environmental Technology, University of Maryland School of Medicine, Baltimore, Maryland, USA.

${ }^{8}$ Santa Fe Institute, Santa Fe, New Mexico, USA.

${ }^{9}$ Los Alamos National Laboratory, Los Alamos, New Mexico, USA.

${ }^{10}$ University of Florida/Space Life Sciences Laboratory, Kennedy Space Center, Florida, USA.

${ }^{11}$ Brown University, Providence, Rhode Island, USA.

${ }^{12}$ Planetary Science Institute, Tucson, Arizona, USA.

${ }^{13}$ Pennsylvania State University, Altoona, Pennsylvania, USA.

${ }^{14}$ Westminster College, Salt Lake City, Utah, USA.

${ }^{15}$ NASA Johnson Space Center, Houston, Texas, USA.

${ }_{17}^{16}$ Foundation for Applied Molecular Evolution, Alachua, Florida, USA.

${ }^{17}$ Universidad Nacional Autonoma de Mexico, Coyoacan, Distrito Federal Mexico, Mexico.

${ }^{18}$ NASA Astrobiology Institute, NASA Ames Research Center, Moffett Field, California, USA.

${ }^{19}$ Denver Museum of Nature and Science, Denver, Colorado, USA.

${ }^{20}$ Space Science Institute, Littleton, Colorado, USA.

${ }^{21}$ University of Minnesota, Minneapolis, Minnesota, USA.

${ }^{22}$ University of New Mexico, Albuquerque, New Mexico, USA.

${ }^{23}$ Princeton University, Princeton, New Jersey, USA.

${ }^{24}$ Texas Tech University, Lubbock, Texas, USA.

${ }^{25}$ New Mexico Institute of Mining and Technology, Socorro, New Mexico, USA.

${ }^{26}$ Northern Arizona University, Flagstaff, Arizona, USA.

${ }^{27}$ College of Charleston, Charleston, South Carolina, USA.

${ }^{28}$ University of Maryland Baltimore County, Baltimore, Maryland, USA.

${ }^{29}$ Lunar and Planetary Institute/USRA, Houston, Texas, USA.

${ }^{30}$ California State University Northridge, Northridge, California, USA.

${ }^{31}$ McGill University, Montreal, Quebec, Canada.

${ }^{32}$ Valparaiso University, Valparaiso, Indiana, USA.

${ }^{33}$ Ecole Normale Superieure, Paris, France.

${ }^{34}$ Wichita State University, Wichita, Kansas, USA.

${ }^{35}$ Technische Universität Berlin, Berlin, Germany; GFZ German Research Center for Geosciences, Section Geomicrobiology, Potsdam, Germany; Leibniz-Institute of Freshwater Ecology and Inland Fisheries (IGB), Department of Experimental Limnology, Stechlin, Germany.

${ }^{36}$ Michigan State University, East Lansing, Michigan, USA.

${ }^{37}$ Delaware State University, Dover, Delaware, USA.

${ }^{38}$ University of Florida, Gainesville, Florida, USA.

${ }^{39}$ University of Texas, El Paso, Texas, USA.
}

A Report from the Conference “Mars Extant Life: What's Next?"; held November 5-8, 2019, in Carlsbad, New Mexico. Conference proceedings available at: https://www.hou.usra.edu/meetings/lifeonmars2019/

(C) B.L. Carrier, D.W. Beaty, M.A. Meyer, et al., 2020; Published by Mary Ann Liebert, Inc. This Open Access article is distributed under the terms of the Creative Commons Attribution Noncommercial License (http://creativecommons.org/licenses/by-nc/4.0/) which permits any noncommercial use, distribution, and reproduction in any medium, provided the original author(s) and the source are credited. 
$\begin{array}{lr}\text { Contents } & 786 \\ \text { Abstract } & 786 \\ \text { 1. Introduction } & 787 \\ \text { 2. Organization of the Ideas Presented and Discussed at the Conference } & 787 \\ \text { 2.1. Definition of key terms } & 788 \\ \text { 3. Martian Environments Deemed to Be Most Prospective for Extant Martian Life } & 790 \\ \text { 3.1. Caves } & 790 \\ \text { 3.2. Deep subsurface } & 793 \\ \text { 3.3. Ice } & 796 \\ \text { 3.4. Salts } & 797 \\ \text { 4. Methodologies: A Summary of Possible Approaches and Strategies to Search for Extant } & 797 \\ \text { Life on Mars } & 799 \\ \text { 4.1. Geologically guided search strategies } & 802 \\ \text { 4.2. Possible detection methods for extant martian life } & 804 \\ \text { 4.3. Possible constraints relevant to the search for extant martian life derived } & 805 \\ \text { from laboratory experiments } & 805 \\ \text { 5. Discussion } & \\ \text { Acknowledgments } & \\ \text { References } & \\ \end{array}$

\section{Abstract}

On November 5-8, 2019, the "Mars Extant Life: What's Next?" conference was convened in Carlsbad, New Mexico. The conference gathered a community of actively publishing experts in disciplines related to habitability and astrobiology. Primary conclusions are as follows: A significant subset of conference attendees concluded that there is a realistic possibility that Mars hosts indigenous microbial life. A powerful theme that permeated the conference is that the key to the search for martian extant life lies in identifying and exploring refugia ("oases"), where conditions are either permanently or episodically significantly more hospitable than average. Based on our existing knowledge of Mars, conference participants highlighted four potential martian refugium (not listed in priority order): Caves, Deep Subsurface, Ices, and Salts. The conference group did not attempt to reach a consensus prioritization of these candidate environments, but instead felt that a defensible prioritization would require a future competitive process. Within the context of these candidate environments, we identified a variety of geological search strategies that could narrow the search space. Additionally, we summarized a number of measurement techniques that could be used to detect evidence of extant life (if present). Again, it was not within the scope of the conference to prioritize these measurement techniques - that is best left for the competitive process. We specifically note that the number and sensitivity of detection methods that could be implemented if samples were returned to Earth greatly exceed the methodologies that could be used at Mars. Finally, important lessons to guide extant life search processes can be derived both from experiments carried out in terrestrial laboratories and analog field sites and from theoretical modeling. Key Words: Mars extant lifeBiosignatures-Life detection-Astrobiology—Life in extreme environments. Astrobiology 20, 785-814.

\section{Introduction}

T HE QUESTION of whether Mars harbors extant life has been pondered by humankind since the time of the ancients. In the more recent past, the work of Giovanni Schiaparelli and Percival Lowell catalyzed widespread speculation that Mars had sentient life. The modern scientific community now universally accepts that such beings do not exist, and focus shifted about 60 years ago to the possibility of extant microbial life. The hypothesis that microbial life may exist in the modern martian regolith was tested during the Viking mission. The results of the Viking biology experiments were equivocal-some aspects of the results were consistent with what would be expected if extant life were present in the samples, but other results were not, thus allowing for multiple interpretations (Levin and Straat, 1981; Zent and McKay, 1994; Klein, 1998; Houtkoope and Schulze-Makuch, 2007). Subsequently, scientists proposed explanations for the $\mathrm{Vi}$ king biology experiment results that do not require the presence of life (Horowitz et al., 1976, 1977; Klein et al., 1976; Oyama et al., 1977; Ponnamperuma et al., 1977; Klein, 1978; Oyama and Berdahl, 1979; Huguenin, 1982; Plumb et al., 1989; Quinn and Zent, 1999; Schuerger and Clark, 2008; Navarro-González et al., 2010; Quinn et al., 2013; Georgiou et al., 2017).

In the modern period (the past $\sim 20$ years), the scientific exploration for life on Mars has split into two intellectual pathways: the search for evidence of ancient life in the martian geological record (while remaining agnostic as to whether or not it may have persisted to the present) and the 
search for extant life. These are documented as Goals 1A and $1 \mathrm{~B}$ in the MEPAG Goals Document (MEPAG, 2018). During the past two decades, beginning with the launches of Pathfinder and the Mars Global Surveyor in 1996, the world's space agencies have sent an unprecedented series of exploratory spacecraft to Mars. Progress has been made on both the ancient and the extant sides of the life question. Without question the search for ancient life has received the preponderance of the attention. This has been driven by the compelling discoveries related to the fact that Mars was far more hospitable early in its geological history than it is today (McKay and Stoker, 1989; Fairén et al., 2010; Kite, 2019). Understanding exactly how similar that environment was to Earth's environment at the time, or to Earth's environment today, remains a hotbed of research.

Recently, there has been tremendous growth in understanding modern life in extreme environments on Earth (Rothschild and Mancinelli, 2001) and how it relates to the limits of life as we know it. This work is just as important to the question of extant life as understanding environmental conditions on Mars and how they have changed in space and time. This has led to revolutionary discoveries related to active life in Earth's deep subsurface and cave environments, including life that can operate at low temperatures or in hypersaline environments, or a combination of both. It has also led to the development of strategies for searching for trace life and measuring its processes.

Finally, based on the improved understanding of the biochemical principles of life as we know it, it has become possible to hypothesize alternate chemical combinations and processes that may lead to life as we do not know it (Schulze-Makuch and Irwin, 2018). This is an important consideration for Mars exploration because assuming that life on Mars has a similar biochemical tool set and functions like life on Earth may unnecessarily limit our thinking.

In order to review and update our understanding of the intersections of the above knowledge, the "Mars Extant Life: What's Next?" conference was convened on November 5-8, 2019, in Carlsbad, New Mexico. This three-and-one-half-day conference was a counterpart to the important conference "Biosignature Preservation and Detection in Mars Analog Environments" (May 16-18, 2016; Lake Tahoe) that addressed the search for ancient life. The conference's Scientific Organizing Committee accepted 82 abstracts, and the conference itself was attended by 71 participants, essentially all of whom were Mars research scientists. The conferees included an excellent mix of junior and senior scientific professionals, postdocs, and graduate students, representing the United States, Mexico, Germany, and France. The venue of Carlsbad was chosen because it offered the chance to observe in the field two important terrestrial analog environments (caves and salt). A one-day field trip was carried out to discuss their essential attributes and relationships "on the outcrop." In Mars planning, it is always imperative to remember that, first and foremost, Mars is a field location.

Specific goals of this conference were twofold. First, to promote discussion of the extant life hypotheses that have developed and evolved in response to ongoing Mars missions. Second, to answer two questions of practical relevance to NASA's Mars Exploration Program. Specifically: (1) Where on Mars does the community advocate looking for evidence of extant life (and how strong are the technical arguments)? (2) What should be the detection methodologies? Spacecraft missions are expensive, and can also be difficult and risky; so in order to justify such missions, the hypotheses need to be clear and compelling and the test (or tests) unambiguous, and there needs to be a broad base of community support that the test is worth doing.

\section{Organization of the Ideas Presented and Discussed at the Conference}

Abstracts submitted to the conference fell into four primary environmental categories that appear to be of greatest interest to the community involved in the search for extant life on Mars: Caves, Deep Subsurface, Ices, and Salts. Additional categories related to methodologies were (1) How to use geologically guided search strategies to find the best candidate sites; (2) Possible detection methods for life as we know it and agnostic life-detection techniques (i.e., for life as we do not know it); (3) Possible constraints on martian life derived from laboratory experiments. These topics became the drivers for organizing the conference sessions and for the structure of this report.

The conference was organized to provide time for group discussion after each session. In order to allow for deeper penetration into each subject area and to help prepare this conference report, the conference participants were broken up into groups of $\sim 6-7$ people for in-depth discussions. Each small group was asked to integrate the conference content in a particular subject area and prepare 3-4 viewgraphs on that topic. These were presented on the last day of the conference. This was followed up by further discussion among the whole group. Effort was put into documenting the primary conclusions, strategies, and open questions developed at the conference. All of this was then synthesized into this report.

\subsection{Definition of key terms}

In order to maximize clarity of communication, we need to be systematic with our terminology. First, we do not know if Mars was ever inhabited, and if so, whether that life persists. For life that may persist to the present day, we use the term "extant life," but without presuming that it actually exists. The Extant Life Conference was about hypotheses related to the possibility of extant life, how to prioritize those hypotheses, and how to test them. When we refer to extant martian life, we are referring to (hypothetical) life that is indigenous to Mars and is distinct from terrestrial life, either due to divergent evolution from a common ancestor or because it has different origins altogether.

In discussing the potential for extant martian life, it is useful to start with certain terminology from the associated field of environmental ecology. "Habitat" is an environment that is occupied by an organism and is traditionally defined species by species. For example, polar bear habitat can be mapped and is distinctly different from the habitat for other species (e.g., for brown bears). However, since we do not know whether indigenous martian life exists at all, and if it does, what its properties are, in this report we have systematically stayed away from the use of "habitat" as applied to one or more (hypothetical) martian organisms. On the other hand, the term "habitat" can be used in the discipline of forward planetary protection, which concerns 
itself with the potential propagation of terrestrial organisms (whose life properties we can measure) in a given martian environment (whose attributes can also be measured).

In recent decades, astrobiologists have used the terms "habitable" and "habitability" as they apply to the search for evidence of life in exotic environments around the Solar System and beyond. "Habitable" is an adjective related to "habitat" (that describes whether or not an environmental niche could be occupied if an appropriate organism was there to do so), and "habitability" is a statement of potentiality (an assessment of the "quality" of an environment to sustain at least one form of life, from anywhere). In this report, we have identified four types of environments on Mars which the community has hypothesized have the highest potential for habitability by as-yet unknown martian organisms. However, it is important to note that there are significant limitations in interpreting habitability for martian organisms using knowledge of terrestrial organisms. We do not have knowledge of the requirements of (hypothetical) martian life. However, as a point of departure we can be guided by our current understanding of the fundamental requirements of life as we know it. We found that the scientists at the conference could unambiguously describe their hypotheses related to "potential habitability" based on this terminology.

\section{Martian Environments Deemed to Be Most Prospective for Extant Martian Life}

Identifying and exploring refugium (an "oasis" where conditions are either permanently or episodically more hospitable than average) as the key to searching for extant life emerged as a powerful theme that permeated the conference. Based on existing knowledge of Mars, we highlighted four martian environments that have the potential to act as refugia (not listed in priority order): Caves, Deep Subsurface, Ices, and Salts. The conference group did not attempt to reach a consensus prioritization of these candidate environments but instead felt that a defensible prioritization would require a future competitive process involving mission proposals. If life originated on Mars in the ancient past and adapted to increasingly hostile surface conditions, a logical hypothesis is that it evolved and retreated into one (or more) of these refugia environments, where it may potentially have survived to the present. Alternatively, life on Mars may have originated in one of these refugia and resided primarily there throughout its existence.

\subsection{Caves}

3.1.1. What do we know about this environment on Earth as a habitat for extant life?. Caves are found in every rock type on Earth and are present on every continent. The rocks that host caves occupy $20 \%$ of Earth's land surface area (Richards et al., 1989; Ford and Williams, 2013). Caves (on Earth) are most frequently developed in carbonate rocks like limestones, dolostones, and marble, and next most frequently occur in basalts (Palmer, 1991; Gillieson, 2009). Caves in carbonate rocks form as aggressive water dissolves the rock whereas those in basalt are lava caves generated during the formation of the rock itself. Terrestrial caves host diverse microbial communities due to the mineral resources and a complex mixture of subterranean and surface pro- cesses (Jones et al., 2019 abstract 5030; Léveillé et al., 2019 abstract 5042; Northup et al., 2019 abstract 5037; O'Connor et al., 2019 abstract 5105; Spilde et al., 2019 abstract 5036). An additional factor that may help explain the diversity of microbial communities in caves is the relatively stable environment which has been theorized to promote diversity in ecosystems and to influence cave mineral form and morphology. For example, caves are relatively isothermal and have relative humidity conditions that can be nearly constant and close to $100 \%$ in the deep (i.e., dark) zone of caves (see Toomey, 2009, for additional details of cave meteorology and monitoring).

The presence of life in cave systems is marked and profoundly alters their physical character. Terrestrial caves aggregate diffuse chemical signals such as metabolic waste by creating preferential flow paths for air and water. Adjacent speleothems show distinct microbial communities (Legatzki et al., 2011) perhaps due to variations in micronutrients. Terrestrial cave air is known to have a significantly different composition than that of the atmosphere due to microbial metabolism (K.D. Webster et al., 2018, 2019 abstract 5048). The formation of autogenic minerals contained in speleothems in caves can capture climate records over geological timescales. Additionally, signs of past life are commonly preserved in terrestrial caves in the form of mineral assemblage suites and unique features like " $\mathrm{u}$ "-loop speleothems and pool fingers (Boston et al., 2001; Northup et al., 2011; Melim et al., 2016; Uckert et al., 2017; Jones et al., 2019 abstract 5030; Northup et al., 2019 abstract 5037).

3.1.2. What do we know about the potential habitability of this environment on Mars?. Caves, due to their confirmed presence (see Fig. 1), have been considered high-priority candidate environments in the search for extant life on Mars (e.g., Boston et al., 2001; Cushing et al., 2007; Blank et al., 2018; Léveillé et al., 2019 abstract 5042). A recent survey using data from the Mars Reconnaissance Orbiter's Context and High Resolution Imaging Cameras has identified more than 1000 candidate cave entrances on the surface of Mars (Cushing, 2017). The cave environment has several advantages over surface targets, including protection from harsh weather, solar radiation, and desiccation. Caves provide direct access to the shallow subsurface, where relatively stable temperatures and humidity conditions could persist over geological timescales, and host ice and salts that are other priority targets in the search for extant life. Additionally, caves on Mars may provide windows into the deep subsurface by virtue of the fact that several meters of rock may be present above the cave. Evidence of biomarkers produced by past life could persist in mineral assemblage suites for long periods of time on Mars given the slow erosion rates. Cave air is thought to exchange with the atmosphere, potentially enhancing the ability to detect such chemical indicators by remote means at their entrances (K.D. Webster, 2019 abstract 5048). Finally, caves offer shelter that could be essential for the human habitation of Mars; thus their exploration robotically has value for science as well future human missions.

3.1.3. Exploration opportunities and challenges. Along with their scientific appeal, martian caves present technological 


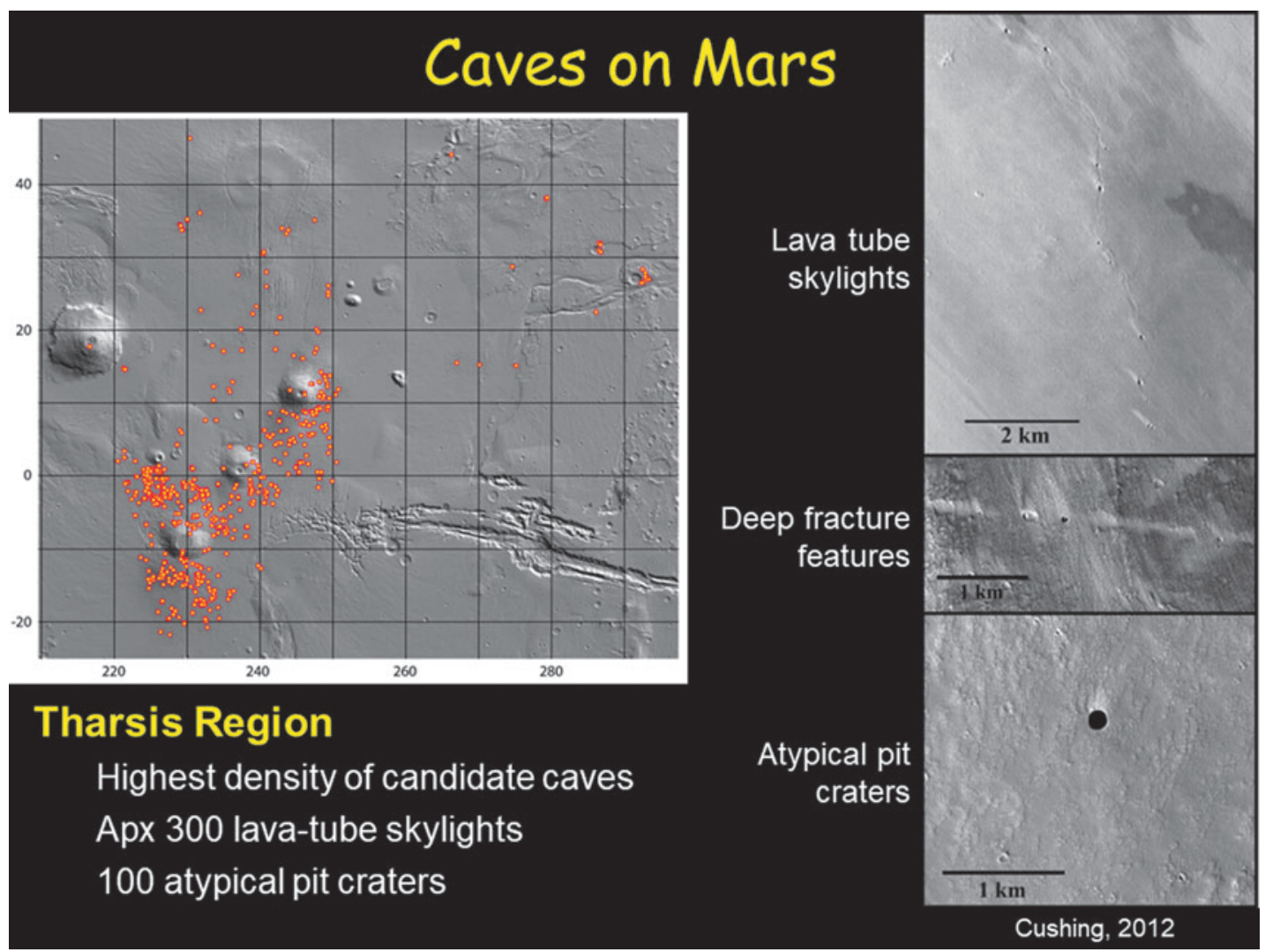

FIG. 1. Over 1000 pits and potential lava cave skylights have been documented on Mars in the Mars Global Cave Candidate Catalog (Cushing \& Okubo, 2016; Cushing, 2017). These possible cave entrances provide numerous targets for the search for life in the martian subsurface. Left: Map of potential cave entrances in the Tharsis Region, where over 300 lava tube skylights and atypical pit craters are concentrated. Map from the Mars Global Cave Candidate Catalog (Cushing, 2017). Right: Three types of candidate caves were cataloged on Mars. Upper right: lava tube skylights; middle right: deep fracture systems; and lower right: atypical pit craters. Image from Cushing (2012). Slide shown by Spilde et al. (2019 abstract 5036) at the conference.

challenges that must be addressed prior to successful exploration. NASA surface missions to Mars have relied on aerobraking from the additional atmosphere of lower-altitude landing destinations, yet the highest cave density is found in the elevated volcanic terrain of Mars' Southern Hemisphere, where the average elevation is kilometers above the mean. Caves at lower elevations do exist and would likely be initial candidate target sites. Entrance points are small relative to a target landing ellipse; thus a surface mission would require a rover rather than a lander in order to relocate to the point of ingress. Cave ingress and dimensions are poorly constrained at present. A variety of robotic approaches have been proposed to overcome obstacles related to entering and navigating inside caves, including (1) Entry from the surface down into the cave system through a skylight, possibly via a large (>50 m) vertical drop, (2) Traversing an irregular floor surface and/or over large blocky obstacles, (3) Operations in darkness, and (4) Autonomous operation and localization (out of line-of-sight to surface communications) ( $c f$. summary in Blank et al., 2018 and references therein). In addition to traditional wheeled rovers, robotic vehicles using biomimicry offer alternative locomotion in challenging subsurface terrain. Prototypes include fleets ("swarms") of coordinating robotic ants, butterflies, dragonflies, and spiders optimized for relay communications away from a control center (see, e.g., Fig. 2) (Blank, 2019 abstract 5108). Most of these technologies are under development for lunar cave exploration and/or in response to the current DARPA Subterranean Challenge (Sitti and Fearing, 2003; Thangavelautham et al., 2014; Wong and Whittaker, 2015; Kalita et al., 2017; Parness et al., 2017; summary table in Blank et al., 2018). Advances and lessons learned will benefit martian cave mission concept development and planning. An initial, successful mission campaign to seek extant life in a martian cave may require a multiphase, multiplatform strategy. This could be accomplished by two Discovery Class or one Flagship mission and would likely require a rover and one or more accompanying crawling or flight drones.

A potential mission concept is outlined as follows. The initial phase would consist of scouting the cave entrance and geology with the use of instruments on board the rover. The cave geometry itself will be assessed through the use of drone swarms and LIDAR to create a $3 \mathrm{D}$ point cloud of the cave. The second phase of the mission will consist of ingress into the cave, detailed mapping, geochemical, and lifedetection assays. After ingress a second drone swarm would be used to map the geochemistry including any water ice present in the cave. The heavier ground-based robot with a high-fidelity scientific payload will assess the key sites identified by the drone campaign. 


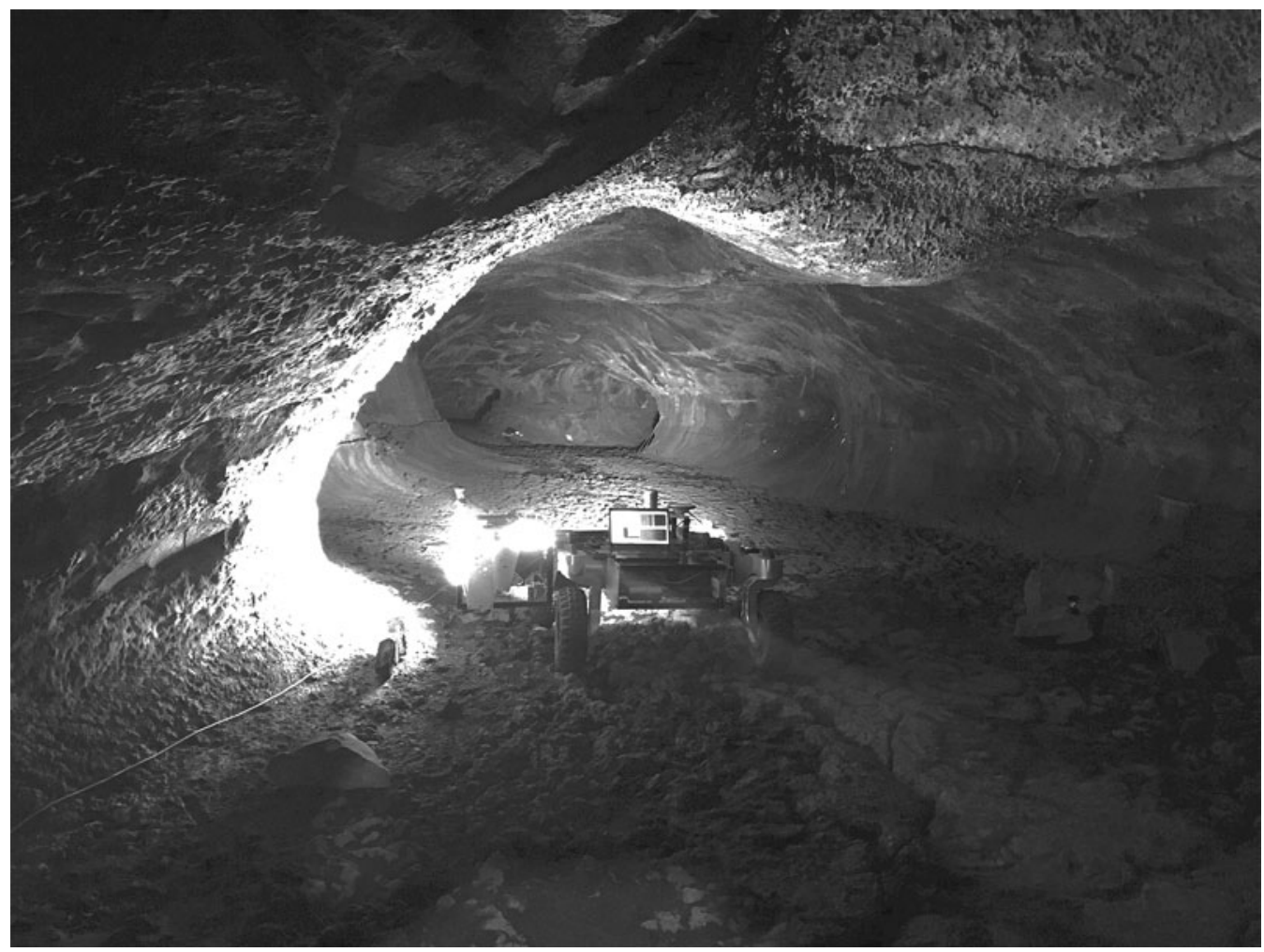

FIG. 2. The NASA Ames K-Rex testing robot, renamed CaveR ("Cave Rover") for its deployment in a volcanic cave at Lava Beds National Monument in northern California. Here, CaveR is shown moving in the down-flow direction inside Valentine Cave, scanning one side of the cave wall. Attached to the rover is a rectangular instrument pod, housing lamps, cameras, and spectrometers that were used to interrogate the cave wall during a Mars mission simulation that was a component of NASA's BRAILLE project. In the future a system like this could be used to explore caves on Mars (shown by Blank, 2019 abstract 5108).

3.1.4. Summary of key arguments for why caves are a compelling target for the search for life.

- There is evidence that large numbers of caves exist on Mars, mostly in the form of lava caves. They have been discovered by means of orbital surveys that have imaged skylights that have broken through to the surface.

- On Earth, caves are invariably associated with uniquely adapted life-forms.

- There is more than one strategy to explore caves for life, including sending a remote vehicle into the cave, and investigating airflow exchange pathways.

\subsection{Deep ${ }^{1}$ Subsurface}

3.2.1. What do we know about this environment on Earth as a habitat for extant life?. Subsurface life on Earth has been found to depths of $>4.4 \mathrm{~km}$ in the continental crust (Purkamo et al., 2020) and $2.5 \mathrm{~km}$ in subseafloor sediments (Inagaki et al., 2015) and could exist at even greater depths that have not yet been explored. It is estimated to contain $\sim 10^{30}$ cells,

\footnotetext{
${ }^{1}$ Although the term "deep" was not quantitatively defined by the conference participants, Fig. 3 shows data for 0 to $\sim 5 \mathrm{~km}$, the recommendations are for tens to hundreds of meters, and the reference to isolated terrestrial groundwater refers to aquifers that are $\sim 1 \mathrm{~km}$ deep. Figure 4 represents the multiple scales of interest.
}

comparable to $\sim 10 \%$ of the total biomass in the surface biosphere and exceeding the microbial biomass in the surface biosphere (Whitman et al., 1998; Magnabosco et al., 2018 and references therein; Onstott et al., 2019a).

In the deep terrestrial subsurface, microbial communities are concentrated in rock-hosted fracture fluids that have often been isolated from surface waters for up to $\sim 10^{7}$ to $10^{9}$ years (e.g., Warr et al., 2018), similar to groundwater isolation timescales expected for Mars, which lacks a significant meteoric water cycle in the present day. Aqueous reservoirs in the deep subsurface can be saline to hypersaline (Sherwood Lollar et al., 2008; Onstott et al., 2019a, 2019b abstract 5025). Microbial communities in these deep subsurface environments on Earth are diverse (Lloyd et al., 2018; Magnabosco et al., 2018), often have low metabolic rates (e.g., Lin et al., 2006), and contain appreciable amounts of biomass with community compositions correlated to in situ lithologies (Magnabosco et al., 2018). The primary producers in many of these deep ecosystems are chemoautotrophs that derive energy from $\mathrm{H}_{2}$ generated by water-rock reactions such as radiolysis, serpentinization in peridotite systems (Schrenk et al., 2013), or oxidation of ferrous silicates, for example, in basalts (Stevens and McKinley, 2000). Hydrogenotrophic methanogens are one common example (e.g., Lau et al., 2016). Sulfate reducers are ubiquitous in the deep, oligotrophic subsurface (e.g., Chivian et al., 2008; Lau et al., 2016; G.S. Lollar et al., 2019) and have been shown to utilize 
A

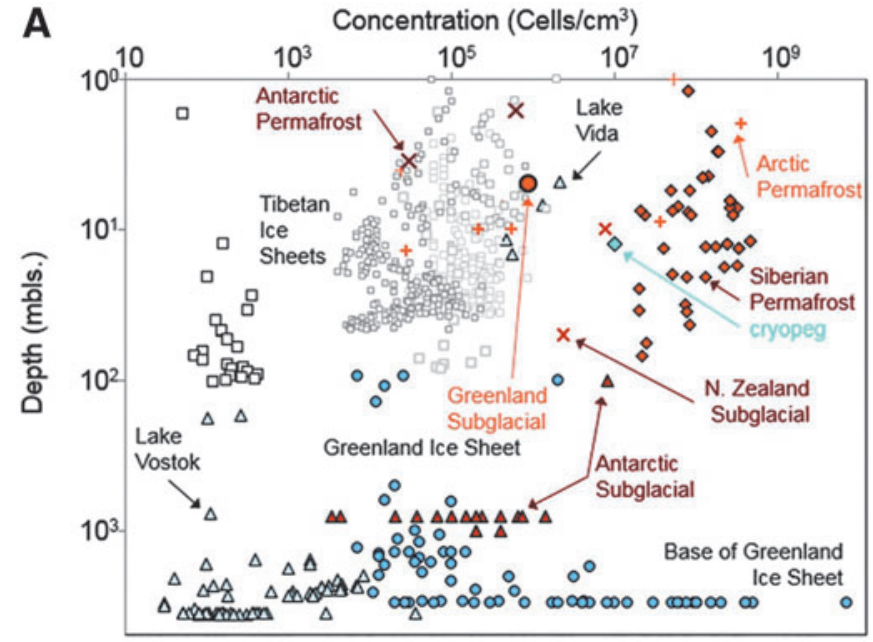

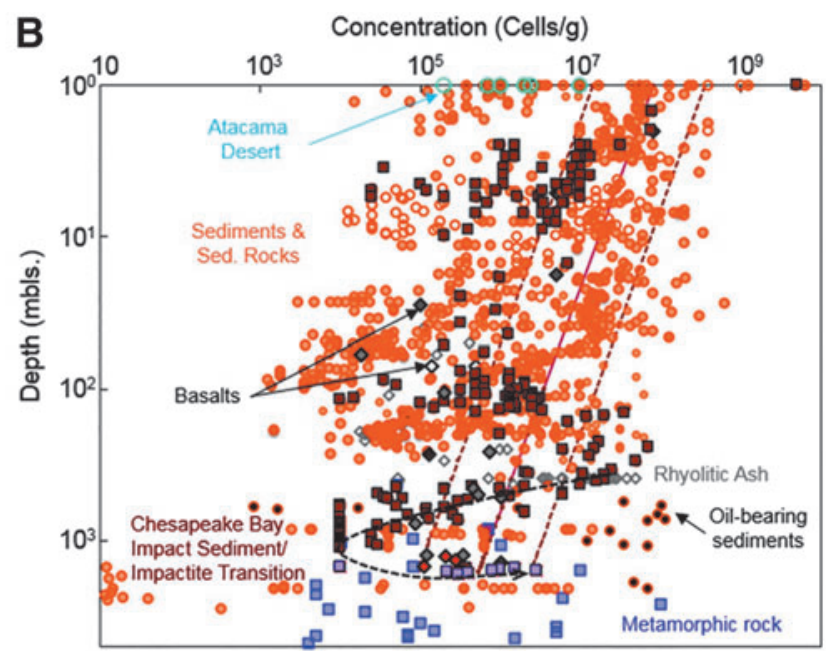

FIG. 3. Distribution of terrestrial subsurface biomass, from Onstott et al. (2019a). (A) Cell concentrations versus depth for ice sheets, subglacial sediments, and permafrost. Open squares=Tibetan glacial ice sheets; brown-filled diamonds = Siberian permafrost; blue-filled diamond = Siberian cryopeg; light gray-filled triangles = Antarctic ice sheets and lakes; brown-filled triangles = Antarctic subglacial sediments; brown crosses = Antarctic permafrost and subglacial sediment in New Zealand; orange crosses = Canadian High Arctic and Svalbard permafrost; light blue-filled circles = Greenland ice sheet; orange-filled circle $=$ Greenland subglacial sediment. (B) Cell concentrations versus depth for rock and soil cores from nonpolar regions. Orange-filled circles $=$ water-saturated sediments or sedimentary rock; orange open circles $=$ vadose zone sediments or sedimentary rock; brown squares = Chesapeake Bay Impact sediments; pink squares = Chesapeake Bay Impact impactite; black-filled orange circles = oil-gas-coal-bearing sediment or sedimentary rock; gray-filled gray diamonds = water saturated rhyolitic ash; open gray diamonds = deep vadose zone rhyolitic ash; open black diamond=vadose zone basaltic rock; gray-filled black diamonds = water-saturated basaltic rock, which includes recent Deccan Trap data from Dutta et al. (2018); red-filled diamonds = Deccan Trap granite data from Dutta et al. (2018); purple squares = metamorphic rock. The rest of the data are from Magnabosco et al. (2018). Blue open circles=Atacama desert soil from Connon et al. (2007) and Lester et al. (2007). Solid and dashed lines represent the best-fit power law for subseafloor sediments proposed by Parkes et al. (2014).

$\mathrm{H}_{2}$ and $\mathrm{SO}_{4}$ derived from radiolysis of pore water and/or the reaction of radiolytic oxidants with surrounding sulfides in many different deep subsurface localities on Earth (e.g., Li et al., 2016; Wei, 2017).

3.2.2. What do we know about the potential habitability of this environment on Mars?. In contrast to the martian surface, where potential habitability is believed to have declined severely early in martian geological history (Fairén et al., 2010; Schulze-Makuch et al., 2013; Cabrol, 2018; Kite, 2019), the deep subsurface is likely the largest and longestlived potentially habitable environment on Mars-possibly existing from the Noachian or pre-Noachian (Michalski et al., 2013; Tarnas et al., 2018; Onstott et al., 2019a) until present day. The habitability of deep crustal reservoirs is indicated from the analogous terrestrial cases of the presence of deeply sourced fluids (carbonic springs, hot springs, and fumaroles) that vent mantle-derived fluids in continental settings in the in the western United States (Crossey et al., 2016), and in large terrestrial impact craters by the presence of substantial fractures as in the uplifted peak ring of the Chicxulub impact crater (Kring et al., 2017).

Thermodynamic and hydrological modeling constraints put the most likely regions for stable liquid water at depths on the scale of kilometers (Stamenković et al., 2019a abstract 5052; see Fig. 4). The existence of widespread liquid groundwater is supported by (i) the measured deuterium-tohydrogen ratio $(\mathrm{D} / \mathrm{H})$, which indicates that the total water loss since the Hesperian has only been about $60 \mathrm{~m}$ (interquartile range 30-120; Grimm et al., 2017); (ii) geological evidence suggesting that ancient Mars up to the late Hesperian ( $\sim 3 \mathrm{Ga}$ ) possessed a $0.5-1 \mathrm{~km}$ thick global equivalent layer (GEL) of $\mathrm{H}_{2} \mathrm{O}$ (Carr, 1987); and (iii) modern-day heat flow estimates of $25 \pm 2 \mathrm{~mW} / \mathrm{m}^{2}$ (Plesa et al., 2016). Away from the polar regions, orbiting radar, such as the Mars Advanced Radar for Subsurface and Ionosphere Sounding (MARSIS), have difficulties detecting groundwater beneath a depth of a few hundred meters. Hence, it is feasible that widespread martian groundwater has so far remained undetectable, although there is radar evidence for liquid water beneath the South Polar Layered Deposits (Orosei et al., 2018).

Organisms with similar metabolisms to those found in the deep subsurface on Earth could exist in the deep subsurface of Mars today (Tarnas et al., 2019 abstract 5104), powered by these same water-rock reactions that require the common geochemical ingredients of radionuclides, water, and reduced $\mathrm{Fe}$ in silicates and sulfides. $\mathrm{CO}_{2}$, which is also a requirement for some of these terrestrial autotrophs, is likely present in the martian subsurface as it is in Earth's deep subsurface (e.g., Ward et al., 2004). If $\mathrm{CH}_{4}$, produced either via methanogenesis or abiotic Fischer-Tropsch type (FTT) reactions, is available in the martian crust as it is in Earth's subsurface (Sherwood Lollar et al., 1993, 2008), then methanotrophic metabolisms could also exist (Harris et al., 2019 abstract 5050). The presence of $\mathrm{CO}$ and/or $\mathrm{O}_{2}$ could support additional metabolisms in the deep martian 


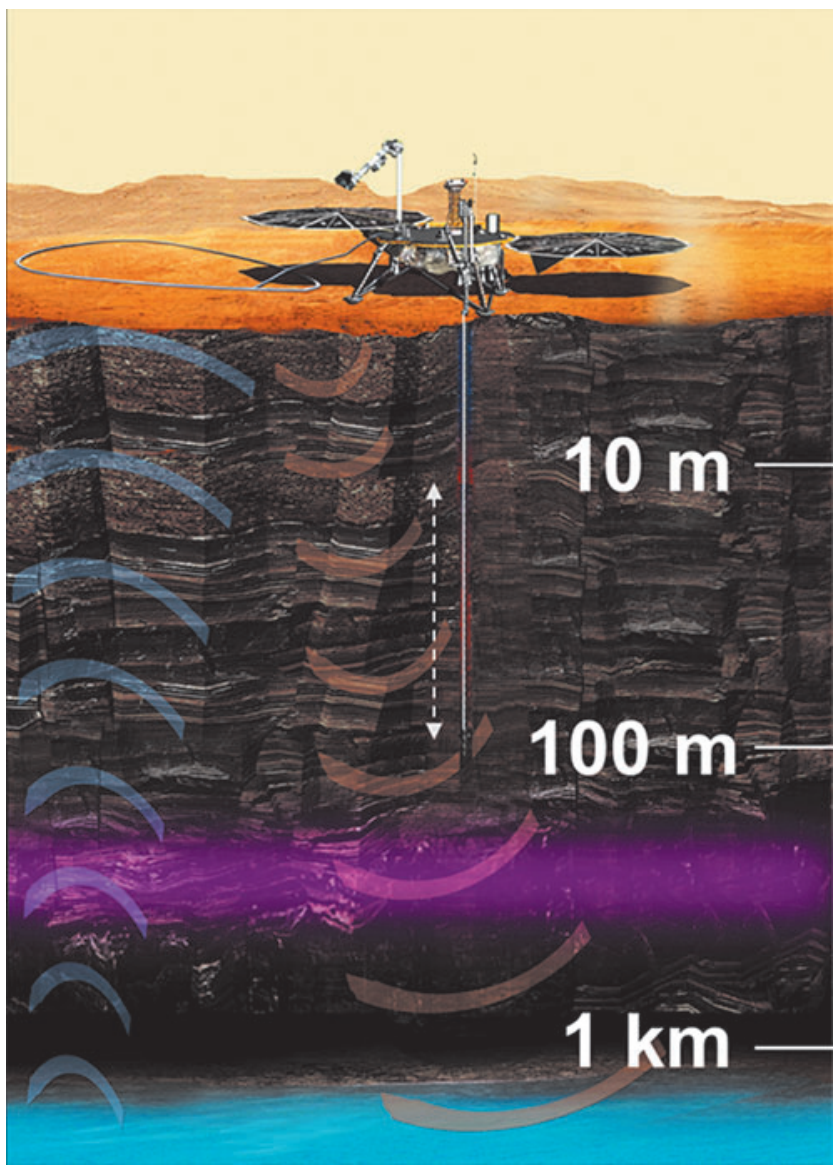

FIG. 4. Schematic cross-section showing the "deep" subsurface exploration target on Mars, with the range of depths of interest. The concept illustrated here is VALKYRIE, which would sound for liquid groundwater and constrain geochemical gradients with depth to establish the first reconnaissance of the martian subsurface habitability trades with depth. Liquid water is expected at depths of kilometers (illustrated with blue shading), but salty brines could possibly exist at shallower depths. Orbiting radar suggest that large-scale brine bodies are not common at depths shallower than $\sim 200 \mathrm{~m}$ (illustrated by the purple shading; see Stamenković et al., 2019b). Shown by Stamenković et al. (2019b abstract 5045) at the conference.

subsurface (Stamenković et al., 2018, 2019b abstract 5045; King et al., 2019 abstract 5029). The habitability of deep martian subsurface sites is probably very high, as in situ physicochemical conditions likely yield sufficient Gibbs free energy for various microbial metabolisms to proceed (e.g., Jones et al., 2018; Harris et al., 2019 abstract 5050). These microbial communities could persist over geological timescales, segregated from increasingly inhospitable surface conditions.

The advantage of potentially habitable deep subsurface environments (where liquid water could continuously exist at depths of several kilometers) is that any martian subsurface life would reside in potentially similar chemical and physical conditions as deep subsurface life does on Earth. Also, deep subsurface life may not need to devote cellular maintenance energy to combat oxidative stress, desiccation, radiation, high salinity, and ultracold conditions that are ubiquitous features of near-surface martian environments including near-surface salts, regolith, or ices.

3.2.3. Exploration opportunities and challenges. Exploration of the deep martian subsurface could be the focus of missions to detect extant martian life, as this potentially habitable environment may be the most similar to its Earth analog, which has hosted active microbial ecosystems living in isolation from surface processes for hundreds of millions to billions of years (e.g., Lippmann-Pipke et al., 2011; Lau et al., 2016; Li et al., 2016; Heard et al., 2018; Warr et al., 2018; Lollar et al., 2019). In the deep subsurface, we can infer potential types of metabolisms to look for, including what processes could produce their driving oxidants and reductants, and what materials might be required for those processes to operate (radionuclides, $\mathrm{H}_{2} \mathrm{O}$, sulfides, ferrous silicates, $\mathrm{CO}_{2}$, and $\mathrm{CH}_{4}$ ). The potential long-term (and macroscale) habitability of subsurface sites is particularly amenable to metabolism-driven life-detection strategies.

Transient electromagnetic (TEM) sounding from the martian surface could be used to characterize subsurface groundwater inventories and chemistries with small spacecraft (target price cap $<\$ 250 \mathrm{M}$ for three small landers) or a Discovery to New Frontiers class budget mission with one single heritage-based Insight-type lander. TEM tools are very common on Earth, and a Mars-applicable conceptual device called $\mathrm{TH}_{2} \mathrm{OR}$ (Transmissive $\mathrm{H}_{2} \mathrm{O}$ Reconnaissance) is currently being developed at NASA's Jet Propulsion Laboratory (JPL), with Technology Readiness Level (TRL) of 6 anticipated within the next 2-3 years (Stamenković et al., 2019a abstract 5052). Aside from sounding, drilling would significantly aid in characterizing modern-day subsurface habitability. A mission concept called VALKYRIE (Volatiles And Life: KeY Reconnaissance and In-situ Exploration; Stamenković $\overline{e t} \overline{a l}$., 2019b abstract 5045) envisions a lander with a liquid water TEM sounder to measure depth, volume, and salinity of liquid water, a deep drill to access the subsurface, a heat probe (not on a mole, but as a sensor on the drill), and a surface biogeochemical analysis package of variable complexity depending on budget. This package could include a Raman spectrometer for in situ characterization of organic species (e.g., Eshelman et al., 2019); a Tunable Laser Spectrometer (TLS) to detect trace gases, their isotopic compositions, and spatiotemporal variations in their fluxes (e.g., C.R. Webster et al., 2018); and instruments such as the Mars 2020 heritage-based Planetary Instrument for X-ray Lithochemistry (PIXL) to characterize chemical variations associated with different rock/ice/salt facies (e.g., Allwood et al., 2015). A drill reaching depths of tens to hundreds of meters would reach deep enough to make these relevant measurements without actually sampling the potentially habitable zones which may exist at greater depths, possibly kilometers below the surface. This would provide a first reconnaissance of the diverse conditions which would affect habitability in the subsurface.

More sophisticated extensions to this concept would extend the drilling depth to where TEM soundings detect liquid water, which is expected to be at a depth of $\sim$ kilometers, and could add more advanced life-detection tools to search for actively metabolizing organisms, or surface mobility to extend the exploration area (Stamenković et al., 2019a abstract 5052). Subsurface exploration of Mars is also 
a key testing ground for technologies required for subsurface exploration of icy moons and in situ resource utilization for future human exploration of Mars. Current drilling technologies, reaching depths of $10-20 \mathrm{~m}$ autonomously, have a TRL of $\sim 5-6$, can be sterilized to Viking standards, and can bring cores to the surface for analyses, preserving stratigraphy and orientation (Zacny et al., 2016; Bar-Cohen et al., 2018; Eshelman et al., 2019). New concepts, such as the Ares Subsurface Great Access and Research Drill (ASGARD) concept (Stamenković et al., 2019b abstract 5045), are being developed at JPL, could extend this depth to $100+m$ with a New Frontiers budget using wireline drilling and $\mathrm{CO}_{2}$ from the martian atmosphere for power and sterile delivery of samples to the surface.

Density estimates of the martian crust from orbital (Goossens et al., 2017) and landed (Lewis et al., 2019) observations indicate that significant quantities of ice and void space (representing caves without connection to the harmful martian atmosphere) likely exist throughout the subsurface. Orbital hyperspectral analysis demonstrates the widespread presence of sulfate and chloride salts on the martian surface (e.g., Ehlmann and Edwards, 2014) that may also exist in the subsurface. As such, exploration of the deep subsurface via sounding or drilling may encompass ice, salts, and rock in both the shallow and deep subsurface, possibly allowing for the full diversity of potentially habitable martian environments to be explored in a single campaign (Stamenković et al., 2019c).

3.2.4. Summary of key arguments for why the (deep) subsurface is a compelling target for the search for life.

- There is evidence that liquid water exists in the deep martian subsurface, although we have thus far been unable to precisely quantify its depth. This environment is inferred to be exceptionally long-lived and stable, similar to its Earth subsurface environment.

- The terrestrial deep biosphere, which has only recently been discovered, is estimated to be the largest reservoir of cellular biomass on Earth.

- Putative martian microbes could utilize oxidants and reductants derived from the same geochemical processes that produce oxidants and reductants in Earth's deep subsurface (radiolysis, serpentinization, FTT reactions).

\subsection{Ice}

3.3.1. What do we know about this environment on Earth as a habitat for extant life?. Terrestrial ice is a habitable environment because it experiences conditions that permit microbial growth and metabolism-namely available liquid water, the presence of solutes and substrates, and temperatures compatible with life. Ice's psychrophilic inhabitants live in liquid brine microchannels and are metabolically active at subzero temperatures. Some can reproduce at temperatures as low as $-18^{\circ} \mathrm{C}$ (Collins and Buick, 1989) in laboratory settings. Evidence of in situ subzero activity also exists. For example, O'Connor et al. (2019 abstract 5105) showed that ice in lava tube caves on Earth (a possible Mars analog) supports metabolically active bacteria.

Ice has the potential to preserve extant-life biosignatures because constant low temperatures slow chemical, cellular, and biomolecular degradation. On Earth, biological mate- rial, organic compounds, and living microorganisms have been found in frozen environments thousands and sometimes millions of years old (Bidle et al., 2007). Survival time of easily degraded molecules is extended in ice compared to warmer environments. For example, DNA from dead organisms has a theoretical degradation time of approximately 10,000 years in temperate environments (Willerslev et al., 2004). Cold environments such as ice and permafrost yield 10-100 fold improvements in preservation time (Bakermans and Whyte, 2019 abstract 5040).

3.3.2. What do we know about the potential habitability of this environment on Mars?. On Mars, recognized icy environments include massive ice in the polar caps, pore space ice, patchy ice, solid ice, bedded ice, pancake ice, veins of ice and sediment-rich ice (Byrne et al., 2009; Rummel et al., 2014; Dundas et al., 2018). Large areas of the martian northern midlatitudes display periglacial geomorphology, suggesting that ground ice is widespread. Recent meteorite impacts suggest nearly pure ice at $<1 \mathrm{~m}$ depth down to $39^{\circ} \mathrm{N}$ (Byrne et al., 2009). Orbital neutron spectroscopy shows an elevated hydrogen signal consistent with water ice in the uppermost meter of regolith at mid to high latitudes (Feldman et al., 2004). Despite these discoveries, ice extent is only broadly characterized. Ice-exposing scarps (Dundas et al., 2018) and recent impact craters (Byrne et al., 2009) can locally constrain the depth of the ice. Increased understanding of midlatitude ice formation and modern stability would help prioritize target areas for extant life in the ice on Mars.

Extrapolating from terrestrial analogs, it is plausible that martian subsurface water ice may provide a potentially habitable environment for extant martian microorganisms in concentrated liquid water veins. Theoretically, liquid water can exist as thin films (veins between crystals) down to $-56^{\circ} \mathrm{C}$ in ice (Rummel et al., 2014). Microorganisms within the original source water are excluded into the liquid veins upon freezing and may persist if the veins remain large enough and they are able to derive energy and nutrients from the high concentration of ions and salts (Junge et al., 2004). The freezing point depression effect of salts (including perchlorate and sulfate salts) may also enhance the habitability of martian ice. Perchlorate salts depress the freezing point of liquid water depending on the associated cations $(\mathrm{Ca}, \mathrm{Mg}, \mathrm{K}, \mathrm{Na}$ ), enabling liquid brines to potentially exist below $-60^{\circ} \mathrm{C}$ (Chevrier et al., 2009). Highly concentrated $\mathrm{NaClO}_{4}$ is liquid at $-73^{\circ} \mathrm{C}$ and has water activity above 0.6 , which is the accepted limit for (terrestrial) life (Toner and Catling, 2016).

Search strategies for life on Mars should also consider ice whose habitability may have been higher in the recent past. Liquid water may occur periodically on Mars at the high northern latitudes. These areas have low elevations (Fig. 51), so atmospheric pressure is high enough to allow liquid water to form at the surface, and they are rich in nearsurface ice (Fig. 5-2 from Feldman et al., 2004). Mars undergoes large periodic variations in the tilt of its orbit (Fig. 5-3 and 5-4), which causes the insolation in the polar regions to vary significantly. This plays a key role in the potential habitability of this ice. For the past 5 Myr, Mars' obliquity has oscillated on $125 \mathrm{kyr}$ timescales around a value of $25^{\circ}$ (Fig. 5-5); however, from 5 to $10 \mathrm{Myr}$ ago, the 

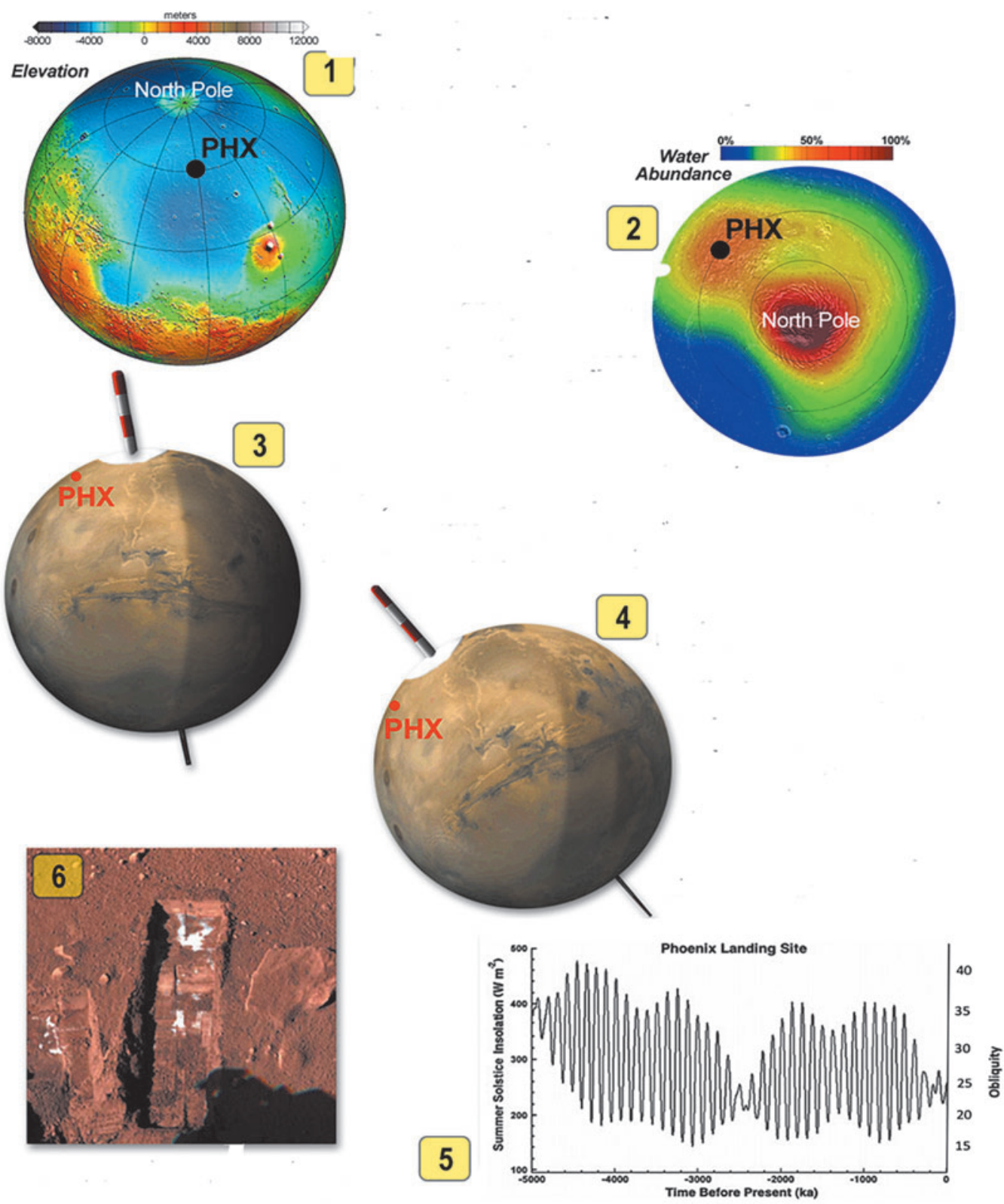

FIG. 5. Elements supporting the potential habitability of high-latitude ground ice on Mars. 5-1 shows color-coded elevation of Mars. The lowest-lying regions are in the northern hemisphere where atmospheric pressure is high enough to allow pure liquid water to form. 5-2 shows water abundance in the upper meter of the subsurface. Red areas are regions of surface and near subsurface ice. 5-3 shows current Mars axial tilt of $25^{\circ}$, and 5-4 shows Mars at axial tilt of $45^{\circ}$ that occurred from 5-10 Myr ago. 5-5 shows how orbital tilt and summer solstice insolation changed over the last 5 Myr at the Phoenix landing site. At high orbital tilt the increased insolation results in summer temperatures that cause melting of ground ice up to $1 \mathrm{~m}$ depth. 5-6 shows "segregated" nearly pure ice just below the surface seen by the Phoenix mission. Shown by Stoker (2019 abstract 5107).

mean obliquity was $\sim 35^{\circ}$ and the maximum almost $50^{\circ}$ (Laskar et al., 2002). At these high obliquities, the maximum insolation is up to 2.5 times the present value, and surface temperatures at $68^{\circ} \mathrm{N}$ latitude exceed $273 \mathrm{~K}$ up to 100 days per year (Richardson and Mischna, 2005). At the Phoenix landing site at $68^{\circ} \mathrm{N}$, ice is only a few centimeters below the surface (Fig. 5-6), and the presence of patches of light-toned ice suggests that thin films of liquid water have migrated through the soil (Mellon et al., 2009), implying that the soils experienced warm enough temperatures to allow this. At obliquity of $45^{\circ}$, temperatures allowing microbial metabolism and growth could persist up to $1 \mathrm{~m}$ depth for long enough time to allow microbial populations to rebound after dormancy periods (Zent, 2008). Potential habitability is enhanced in silty soil with $\sim 1 \%$ perchlorate as measured by Phoenix (Sizemore et al., 2019 abstract 5101).

3.3.3. Exploration opportunities and challenges. Ice-rich terrains on Mars are well characterized and generally accessible sites in which to search for potential modern life on 
Mars. Potential missions to search for life in the ice-rich martian terrains were reviewed (Eigenbrode et al., 2019 abstract 5020; Stoker, 2019 abstract 5107; see Fig. 6). These missions are enabled by advances in automated drilling technology, and 1 and $2 \mathrm{~m}$ drilling systems will be flown in the near future. Stoker (2019 abstract 5107) reviewed the proposed Icebreaker Discovery Class mission that plans to return to the Phoenix landing site and search for biosignatures of life, using the same lander system as Phoenix and InSight. The proposed payload includes a $1 \mathrm{~m}$ augering drill to retrieve samples to be analyzed by (1) a gas chromatograph-mass spectrometer that chemically separates compounds relevant to biological processes prior to volatilization and has sufficient sensitivity to reveal features that may distinguish between biotic and abiotic sources; (2) the Signs of Life Detector (SOLID) (Parro et al., 2011) that uses immunoassay to search for larger peptide compounds only produced biologically; and (3) the Wet Chemistry Laboratory to measure soluble ions that provide potential sources of nutrients and metabolic energy for life. Like Phoenix, Icebreaker would land in Northern spring and have a short mission duration limited by seasonal sunlight availability. Alternatively, many potential sites with near subsurface midlatitude ice could be explored with a rover carrying a drill. The ExoMars rover's $2 \mathrm{~m}$ core drilling system could reach and sample ground ice with (presumably) minimal modification. Other scenarios reviewed at the meeting (Eigenbrode et al., 2019 abstract 5020) involve multiple assets, such as a rover capable of high-resolution remote sensing and ground-ice sample acquisition that delivers samples to a laboratory lander nearby, or multiple small rovers networked and operating autonomously with a base spacecraft orbiter, or a human-staffed space station. This type of approach would be advantageous for expandable mission scenarios that would also be capable of addressing other science objectives.

A better understanding of midlatitude ice formation and modern stability would help prioritize target areas for searching for extant life in ices on Mars. Experiments should be done under a variety of Mars-like conditions, including with salts that can depress the freezing point of water interlayered or mixed with permafrost (ice/regolith). More detailed experiments and modeling would help determine the extent to which metabolism and the growth of microbes in subsurface ice in the midlatitudes is possible under varying conditions (e.g., at different obliquities, salt concentrations). Such modelling and experimentation could greatly inform the sampling strategy and also constrain the potential risk of biological contamination from human missions to ice-rich areas.

3.3.4. Summary of key arguments for why ice is a compelling target for the search for life.

- Permafrost and ice mixed with soil or sediments may have all the components needed for modern martian life including (1) Chemical and mineral compositions that can release soluble nutrients; (2) Electron donors and electron acceptors; and (3) Sufficient carbon, nitrogen, and phosphorus to enable biological reproduction and growth.

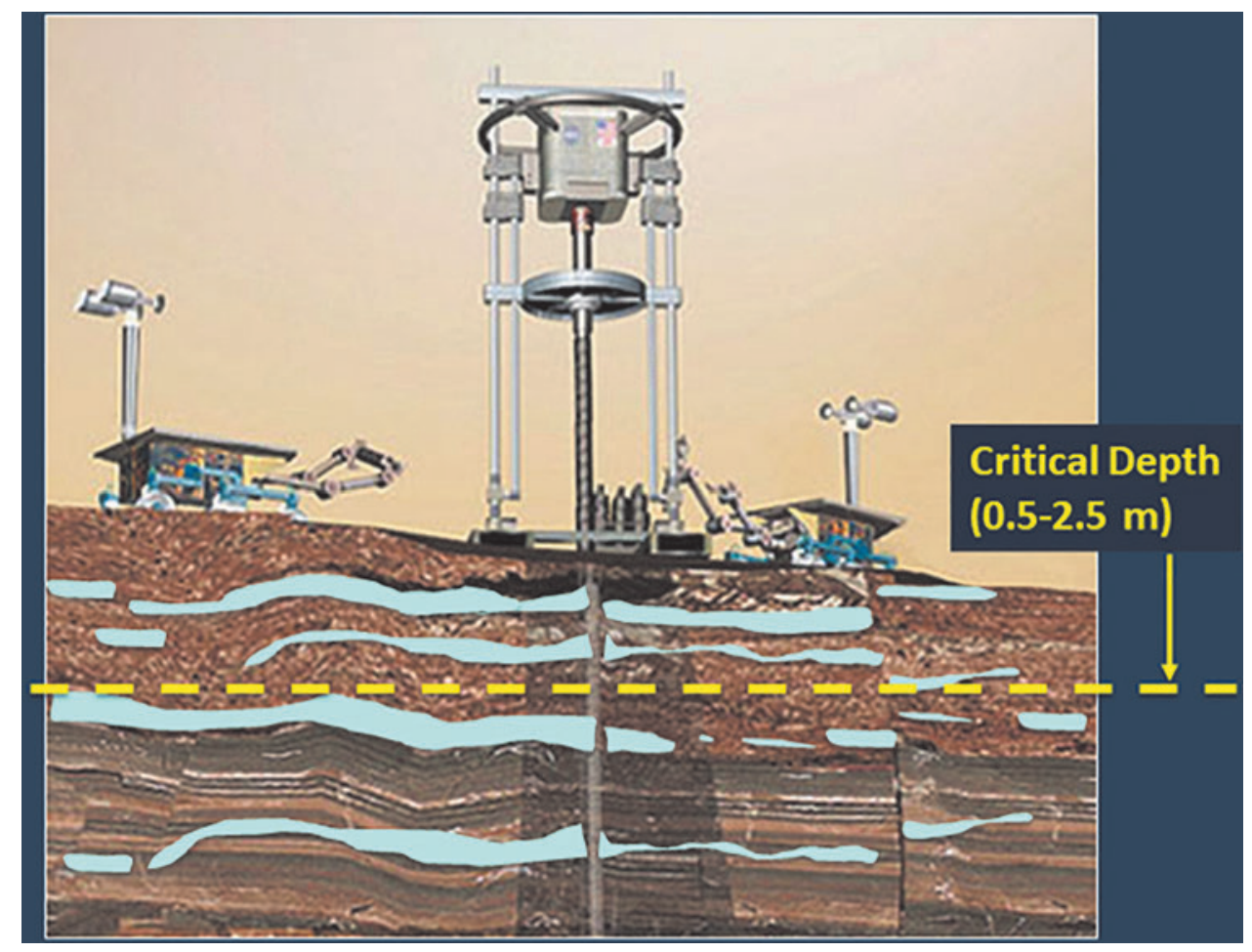

FIG. 6. Schematic of rovers operating a drill on Mars to access pockets of ice in the near subsurface. The critical depth marks the boundary in which conditions favored recent habitability (within $10 \mathrm{Myr}$ at a time of high obliquity) in terms of both water activity and radiation tolerance. Current models place the critical depth at $0.5-2.5 \mathrm{~m}$ depending on location. Schematic modified from an original produced by NASA/JPL. 
- Temperatures in shallow subsurface ice vary quasiperiodically, driven by insolation changes associated with orbital forcing; some periods may allow shallow subsurface ice to be warm enough for brine stability. Indigenous martian life may have evolved to be able to inhabit this environment at temperatures significantly lower than those that exist in terrestrial ice.

- Ice is widespread in the near-surface of Mars, existing from $\sim 35-90^{\circ} \mathrm{N}$ latitude and about $\sim 45-90^{\circ} \mathrm{S}$ latitude. Many ice-rich targets in the near subsurface are easily accessible for exploration and sampling.

\subsection{Salts}

3.4.1. What do we know about this environment on Earth as a habitat for extant life?. Salts and saturated brines on Earth exhibit many unique and compelling qualities that make them relevant to the search for extant life on Mars (Mancinelli et al., 2004). Earth has been covered by salty oceans from an early time in its history, commencing soon after the formation of the planet 4.6 billion years ago. Through the process of wetting and drying, brines, evaporates, and salts have been deposited globally over time. These hypersaline environments have been and continue to be highly productive biologically, with the development of diverse microbial communities, including phototrophs, lithotrophs, and heterotrophs, giving rise to dense microbial mats and stromatolites (DasSarma and Arora, 2017; DasSarma et al., 2019; Perl and Baxter, 2020). Halophilic microbial communities formed more than a billion years ago and are preserved as fossilized stromatolites, and they still form in brines and evaporites on modern Earth. Within salt deposits, enclosed brine fluids can be preserved, whether fluids are recent (active groundwater movement) or geologically old (closed aquifers). These brine environments have been of great interest to evolutionary biologists due to isolated extant microorganisms, potentially as evidence of ancient biology. As a result, the importance of the salt-water nexus for supporting life in general cannot be overstated, given the universal role of cellularity and chemiosmotic coupling for bioenergetics on Earth (Schoepp-Cothenet et al., 2013).

Salts have outstanding preservation potential for biological materials, underscored by the finding of complex microbial communities contained in minerals and fluid inclusions on Earth (Holt and Powers, 2019 abstract 5046). Moreover, modern stratified communities of endolithic phototrophs have been found associated with gypsum crusts, and entrapped halophilic bacteria and archaea have been isolated from halite crystals, with striking and easily detectable carotenoid pigment biosignatures (see, e.g., Fig. 7; DasSarma et al., 2019; DasSarma and DasSarma, 2019 abstract 5092; Perl et al., 2019 abstract 5031). Additionally, halite, gypsum, and other minerals offer radiation protection by attenuating UV light, a significant challenge on the surface of Mars, with deliquescence protecting from long-term desiccation, and hydrated and hygroscopic evaporites representing additional potential liquid water sources for extant life (Davila et al., 2010). As a result, salts provide highly desirable microenvironments in the search for life on Mars (Davila and Schulze-Makuch, 2016; SchulzeMakuch, 2019 abstract 5009). Finally, salts and evaporites may also contain trapped chemicals potentially resulting from ongoing evolutionary processes, which may be readily detected as a result of concentration of dissolved components (Zorzano et al., 2009; Clark and Kolb, 2019 abstract 5008). For example, iron is widely distributed on Mars and is essential to life on Earth due to its role in electron transfer reactions, and its salt solutions exhibit low eutectic temperatures, making such concentrated brines potentially favorable for supporting life or its emergence (Chevrier and Altheide, 2008). Salts also extend the temperature range for liquid water by freezing point depression and formation of supercooled liquids, forming in ice veins, and expanding the possibility of supporting life processes over a wide temperature range, not only on Earth but on even colder worlds, including the nearsurface of Mars (Toner et al., 2014). Evaporitic environments therefore represent excellent targets for discovery science
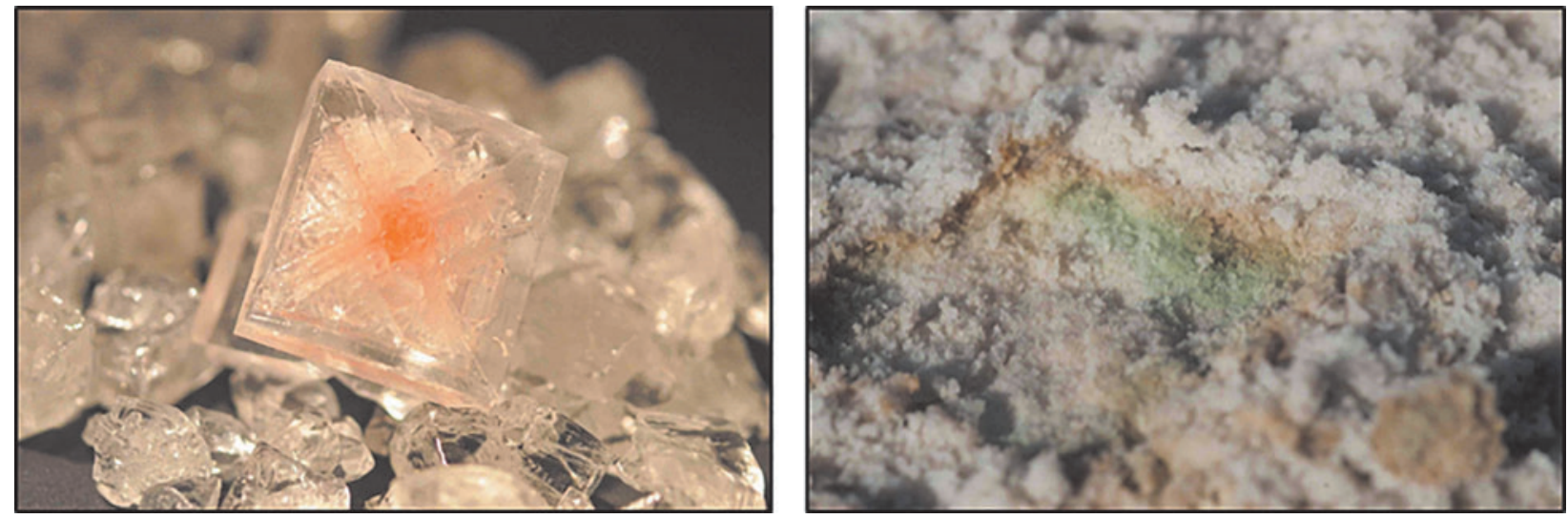

FIG. 7. Examples of terrestrial microbes that can be found in salt deposits. Left: Pigmented halophilic microorganisms such as haloarchaea may survive entombed in halite crystals and are detectable from spectroscopic properties of carotenoids. Adapted from Microbe, Vol 5, no. 3, cover image, courtesy of Priya DasSarma and Christopher Jacob, UMB (C)ASM, and shown at the conference by DasSarma (DasSarma and DasSarma, 2019 abstract 5092). Right: Stratified endolithic halophilic microbial communities are common below the gypsum layer, such as in White Sands National Monument, New Mexico, and display characteristic red and green layers. Courtesy of Benjamin Brunner and Jie Xu, UTEP. Shown at the conference by Xu (LaJoie et al., 2019 abstract 5051). 
missions to Mars related to the origin of life, persistence of life, and finding extant life.

3.4.2. What do we know about the potential habitability of this environment on Mars?. Although $\mathrm{Cl}$ atoms are ubiquitous and detected at unusually high levels in soils, rocks, and sediments by all surface missions to Mars, the values typically cluster between 0.5 and $1.5 \mathrm{wt} \% \mathrm{Cl}$, and levels above $4 \mathrm{wt} \% \mathrm{NaCl}$ equivalent are rare (Clark and Kounaves, 2016). However, environments much higher in $\mathrm{Cl}$ have been discovered and extensively mapped from orbit, with many sites in local depressions and higher terrains resulting from surface runoff, groundwater upwelling, and hydrothermal activity (Osterloo et al., 2010). For example, the Eastern Margaritifer Terra in the equatorial region contains mineral precipitation in upwelling fluids from crater floor fractures and was rated highly for the Mars 2020 landing site, while Columbus Crater in Terra Sirenum contains groundwater-fed paleolakes with evaporite salts and is being considered as a human exploration zone (Wray et al., 2011; R.J. Thomas et al., 2017). Jezero Crater, the selected Mars 2020 landing site, also contains hydrated minerals in outflow deposits within the river deltas that have been captured by the CRISM (Compact Reconnaissance Imaging Spectrometer for Mars) and HiRISE (High Resolution Imaging Science Experiment) instruments on board the Mars Reconnaissance Orbiter. If life exists today on Mars, or existed in the recent past, microscopic examination of such evaporite minerals and their fluid inclusions might offer a straightforward and realistic way to confirm its existence, while spectroscopic analyses may uncover biochemicals that represent biosynthetic or breakdown products of life. Moreover, having these features as potential targets for future Mars Sample Return efforts would allow for potentially concentrated organics and extant life analyses within its mineral structure. Salts and brines containing concentrated dissolved solutes and gas pockets could serve as energy and nutrient resources for life (e.g., perchlorates, nitrates, sulfates, organics, methane), with near-surface evaporites additionally providing access to sunlight for potential phototrophic activities (DasSarma and DasSarma, 2019 abstract 5092; LaJoie et al., 2019 abstract 5051; Lynch et al., 2019a, 2019b abstract 5056; Pavlov et al., 2019 abstract 5057). Consequently, when considering NASA's current mission concepts, evaporitic environments at the surface and near subsurface offer targets that are likely to be readily accessible to robotic exploration.

3.4.3. Exploration opportunities and challenges. For the discovery of extant life at the martian near surface, mobile platforms may be used to locate and sample evaporitic environments in current and future life-detection missions. One major advantage of salts as a potentially habitable microenvironment is that they may provide a protected environment for extant life on Mars very close to the surface and may harbor phototrophs (Davila and Schulze-Makuch, 2016; S. DasSarma et al., 2019). The salts themselves may serve as a UV shield, while allowing the limited sunlight to be accessible to the microbes. Many heritage flight instruments that can detect common biomolecules diagnostic of extant life (nucleic acids, proteins, lipids, pigments, ATP, etc.) already exist, including UV/VIS/IR, MS, fluorescence, and Raman spectrometers, and can be used to characterize brine chemistry (N.H. Thomas et al., 2019; Stromberg et al., 2019). Considerable heterogeneity in salts and minerals is expected, characterization of which should be pursued in order to assess the potential of evaporites to harbor life. Perhaps most importantly, improvement of remote microscopic visualization technologies (e.g., the Mars Hand Lens Imager [MAHLI] on the Mars Science Laboratory) capable of searching for and imaging fluid inclusions is needed. Among these approaches, the ability to test motility (e.g., photo-attractant [VIS] or photo-phobic [UV] responses) is highly desirable and could establish properties commonly observed for living microorganisms. This could be used to readily detect life within the brine inclusions. Improved labeled release and chirality tests also will be highly informative, including stimulatory effects from the addition of gases and nutrients. Some of the assays may require testing for potential interference from salts which could challenge some existing analytical methods and warrant appropriate modification prior to use in high-salt environments.

3.4.4. Summary of key arguments for why salts and evaporites are compelling targets for the search for life.

- On Earth, evaporites and associated brines are known to support a wide diversity of microbial life, phototrophs, lithotrophs, and heterotrophs.

- Fluid inclusions trapped in solid and crystalline salts (on Earth) contain dissolved chemical nutrients that can support life, with enhanced preservation potential for biological materials, and considerable evidence for extant life itself (possibly of significant geological age).

- Salt deposits are widespread on the surface of Mars, especially in the southern hemisphere, and are readily accessible by rovers. Near-surface exploration accessibility makes salt deposits a favorable target for exploring for extant life on Mars.

\section{Methodologies: A Summary of Possible Approaches and Strategies to Search for Extant Life on Mars}

\subsection{Geologically guided search strategies}

4.1.1. Overview. A geologically guided strategy characterizes promising sites over a range of spatial and temporal scales, linking orbital, rover, rock, mineral, and chemical observations. This approach recognizes that evidence for extant life is likely heterogeneously distributed with respect to both its location and its occurrence in the recent past (e.g., Des Marais, 2019a abstract 5023). If the origin of a biosignature can be confirmed to be geologically recent, then it likely indicates that life still exists somewhere. Accordingly, determining the age of any promising deposits is centrally important to the search. Critically, a geologically oriented search for extant life investigates multiple indicators of recent environmental conditions and diverse types of biosignatures. Interpretations based upon a mutually consistent array of environmental indicators and potential biosignatures could lead to the most definitive evidence of extant life.

4.1.2. Potentially habitable environments differ in "quality.". Because habitability is a key prerequisite for life, 
only locations that were or are plausibly habitable should be considered as potentially harboring extant life on Mars. However, it is important to recognize that while there are many types of habitable environments on Earth, not every habitable environment provides an equal likelihood of encountering life. The spatial heterogeneity within these environments can make life (and the preservation of its signatures) "patchy" in nature, thereby lessening the likelihood of its detection. A geological strategy must assess the heterogeneity of both spatial and temporal distribution of the most promising sites for exploration. Potentially habitable environments must simultaneously furnish raw materials $(\mathrm{C}, \mathrm{H}, \mathrm{N}, \mathrm{O}, \mathrm{P}, \mathrm{S})$, a suitable solvent (liquid water), metabolically useful energy, and clement conditions (Fig. 8). Relatively clement conditions of temperature, $\mathrm{pH}$, salinity, radiation protection, and so on are more favorable for life detection because they require less energy to cope with the environment, so life can become more abundant. On Earth, as an environment gradually becomes less favorable, life retreats to "hotspots" in which better conditions may be maintained, creating islands of extant life separated by wide swaths of sterile ground (Davila et al., 2019). Likewise, any evidence of martian extant life is very likely to be sparsely distributed, both spatially on the presentday surface and across geologically recent timescales (Boston et al., 2019 abstract 5058). Therefore, the choice of potentially habitable environment is a key part of searching for extant life. While many environments may be plausibly habitable, the selection of environments that are likely to be habitable will greatly increase the chances of finding extant life and reduce the likelihood of having to search for "a biological needle in an abiotic haystack" (Davila et al., 2019).

4.1.3. Biosignature types. Given our understanding of the "patchy" nature of some potentially habitable environments, on Mars, differences between biosignatures (i.e., biological "signals") and abiotic features (environmental "noise") might be far less distinct than they are on Earth. This is particularly true for "life as we do not know it." Potentially habitable planetary environments also create nonbiological features that can mimic biosignatures, so these environments must be characterized to the extent necessary to confirm the presence of potential biosignatures. To mitigate this issue, a geological strategy would suggest searching for several additional classes of biosignatures, including organic molecules, minerals (Lanza et al., 2019 abstract 5035; Yeager et al., 2019 abstract 5060), other chemistry (Gasda et al., 2019 abstract 5034; Nellessen et al., 2019 abstract 5102), stable isotopic patterns, and biological macrostructures and microstructures (see Fig. 8). Biosignatures of extant life might have accumulated over time in geologically recent epochs. On Earth, abundant sedimentary bioorganic matter (Des Marais, 2001) and ubiquitous Precambrian stromatolitic carbonates (Walter, 1994) illustrate how persistent habitable conditions have allowed biosignatures to accumulate over time, thus becoming widespread and abundant. The challenge on Mars, of course, will be to identify and map the distribution of any potentially recent habitable environments.

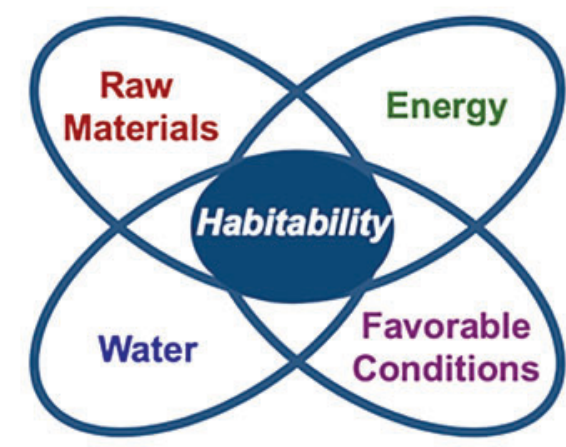

Adapted from Tori Hoehler

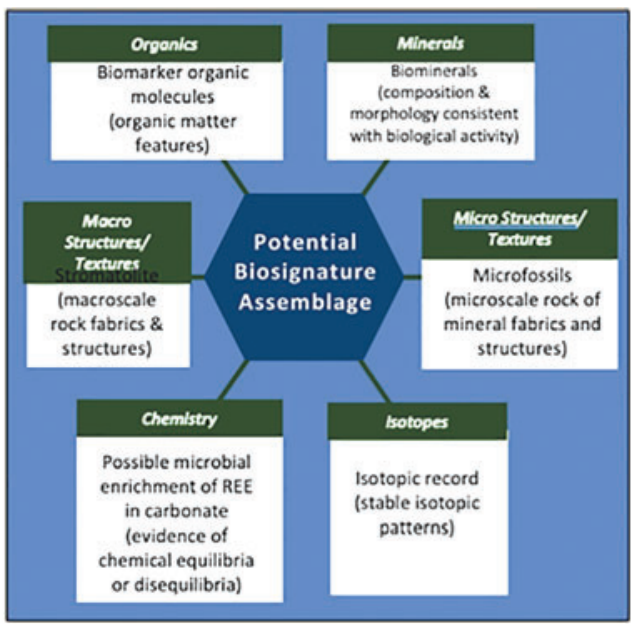

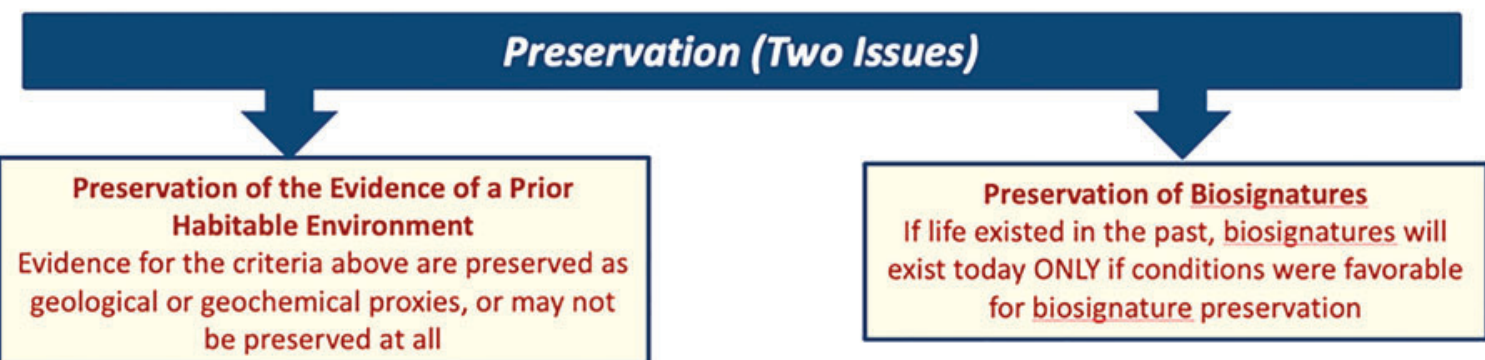

FIG. 8. Schematic diagrams depicting attributes of habitable environments, types of biosignatures, and issues surrounding the preservation of environmental indicators and biosignatures which can be used to inform the search for evidence of life (from Des Marais, 2019a abstract 5023). 
4.1.4. Characterizing environments, biosignatures, and preservation from orbital to microscopic scales. With the above understanding of habitability and biosignatures in mind, applying a geological strategy for the search for life on Mars requires an integrated approach to characterizing the martian surface over a range of spatial scales to ensure that signatures of interest are consistent with each other and with the broader context. At the macroscale, orbital observations provide a planet-wide search for evidence of past and (potentially) recent habitable environments (Allen and Oehler, 2019 abstract 5011; DasSarma and DasSarma, 2019 abstract 5092; Elaksher, 2019 abstract 5094; Scuderi et al., 2019 abstract 5043; J.M. Williams et al., 2019 abstract 5021). A key question is how recently and for how long liquid water occurred at localities accessible by spacecraft. Orbital mapping can identify aqueous deposits associated with outflow channels, seeps, deltas, fans, faults, and craters (Newsom et al., 2019 abstract 5049; Scuderi et al., 2019 abstract 5043). Some of these features might be linked to deep aquifers where extant life found refuge from unfavorable surface conditions including changing climate, large impacts, and solar variability (see Sections 3.1 and 3.2 for more detailed discussion of the subsurface environments). Orbital observations also can map minerals that, on Earth, preserve biosignatures, for example, silica, carbonates, evaporites, phyllosilicates (Farmer, 1999), and iron oxides (Hays et al., 2017). Geomorphological evidence can identify outcrops that were recently exhumed and thus experienced less radiation damage.

At the outcrop scale, sedimentary textures and fabrics can identify key environmental processes and conditions such as subaerial versus subaqueous sedimentation, sedimentation rate, turbulence, salinity, and water depth. At the rock scale, the order and function that are intrinsic to living systems can be expressed as structures characteristic of the organisms themselves and as structures and "bio-fabrics" that they create in their surrounding environments (e.g., S.S. Johnson et al., 2019a). Important examples include cells, organized cell clusters, biofilms, bioherms (mounds built by microbes) and bodies of multicellular life (Des Marais and Jahnke, 2019). Many fabrics can survive burial and storage in geological deposits more robustly than the microbes that created them. However, discussions of textures and fabrics were under-represented at this meeting.

At the mineral and grain scale, mineral assemblages characterize environmental conditions such as temperatures, solute concentrations, redox conditions, water-to-rock ratios, and sources and rates of sedimentation. Some carbon-bearing minerals and metal oxides probably occur exclusively because of biological activity (Hazen et al., 2008). As the major component of living tissue, organic matter is likely to retain diagnostic evidence about the nature of biochemical activity (Des Marais, 2019b). Some of these compounds can persist as biosignatures in geological deposits. Certain metals occur in relatively smaller abundances but have essential biochemical roles (Lanza et al., 2019 abstract 5035; Yeager et al., 2019 abstract 5060). Biochemical processes also can affect the stable isotopic compositions of reactants and product molecules in ways that differ from those caused by nonbiological processes. A detailed understanding of geological context through multiple observations of habitability and potential biosignatures will point to promising regions on the martian surface that offer the best chance of encountering extant life on Mars.

\subsection{Possible detection methods for extant martian life}

4.2.1. Overview. The operational definition of life from NASA is "a self-sustaining chemical system capable of Darwinian evolution" (Joyce, 1994), which includes both life as we know it, based on Earth biochemistry, as well as life based on other exotic biochemistries. This leads to the three different approaches for looking for extant life, which are described below. Depending on the initial assumptions, in situ life-detection methods can be either agnostic, meaning that they do not depend upon martian life being similar to terrestrial life, or can be performed under the assumption that any extant life on Mars would be biochemically similar to terrestrial life. The third approach, which requires return of sample material to Earth, would allow for both types of investigations and for a far larger number of measurements than can be made in situ.

4.2.2. Agnostic life detection. When searching for unknown life-forms, without presupposing a terrestrial-like molecular basis, investigation strategies should focus on looking at universal signatures of biology (otherwise known as agnostic biosignatures), rather than on known terrestrial biosignatures. As mentioned above, the first step could focus on chemical analyses, especially those than can be performed using high heritage space-capable instruments. In this step it would be of particular importance to keep in mind that life elsewhere could be composed of biochemistries that are thus far unimaginable to us; therefore it is vital to abstract our search and define certain features of chemistry that we would expect to be present in any form of life (S.S. Johnson et al., 2019 b abstract 5026). With this in mind, chemically agnostic biosignatures could involve searching for molecular complexity or patterns of molecular complexity that are distinct from randomly produced structures (see Fig. 9). If a sufficiently complex molecule is found in significant abundance in a sample, it may be a product of biology (Marshall et al., 2017). Similarly, if only a small subset of molecules within a class are found in an otherwise heterogeneous sample, then logically this could indicate a focused metabolism that may be a product of biology. These analyses could be performed using mass spectrometry with an agnostic approach that assumes that the features of chemical compounds produced by life will be distinct from the random compounds that are produced by abiotic processes in typical space environments (Mahaffy et al., 2019 abstract 5022). Mass spectrometer-based instruments have been used in many Mars missions since the Viking missions. Tandem mass spectrometry (MS/MS) allows the isolation of ions of interest, targeting specific species within a complex sample, thereby supporting detailed chemical identification of unknown compounds, and will be used for the first time in space on the ExoMars 2020 rover. The collected mass spectra can then be used to determine if there are fragmentation patterns exhibited by molecules that could potentially be of interest and warrant further investigation (S.S. Johnson et al. 2019b abstract 5026). Another proposed avenue to explore is to look for the presence of polymers with a constrained set of building blocks (Benner 2019 abstract 5112), which is proposed to be an essential component of 


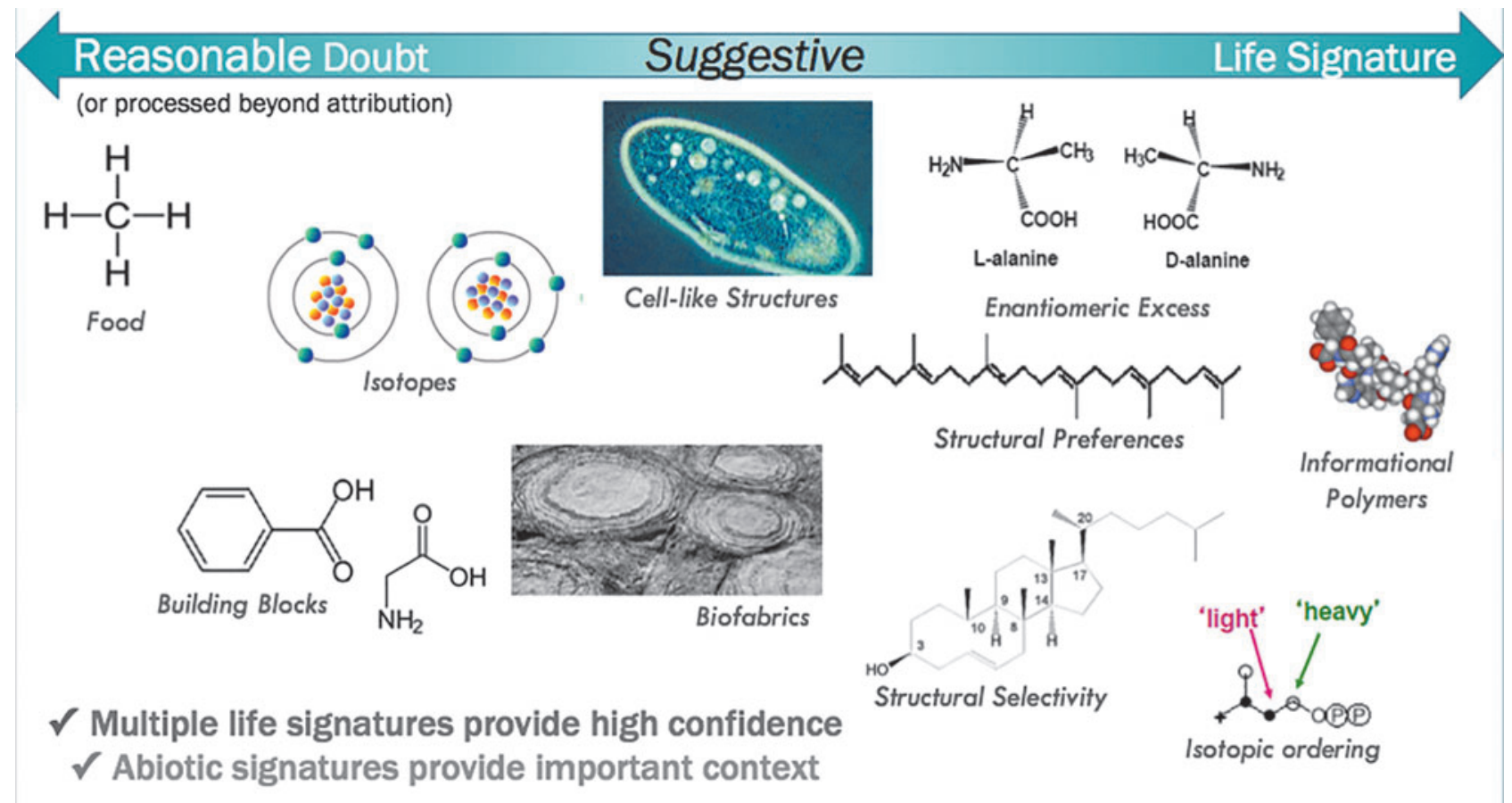

FIG. 9. Some examples of measurements that could be made in support of Mars extant life detection. There are a range of potential biosignatures that can be detected which range from materials that could be either biotic or abiotic in origin (left) to materials that are very unlikely to be produced in the absence of life (right). Detection of multiple "life signatures" would provide strong evidence for the presence of life, while abiotic signatures could provide important context. Shown by Mahaffy et al. (2019 abstract 5022; from Getty, 2018) at the conference.

biology (by expanding the chemical space through functional polymers, and the safeguard of propagatable information) (S.S. Johnson et al., 2019b abstract 5026). Other standard chemical biosignatures that are agnostic of the biochemistry are overabundance of certain elements and isotopes, enantiomeric excess within a class of compounds, or an overabundance of chiral compounds in general. These chemical analyses can be conducted with instruments such as mass spectrometry, vibrational spectroscopy, or fluorescence.

Another agnostic biosignature discussed was complexity (or heterogeneity), which can be explored through the newly proposed "fingerprinting" method (Johnson et al., 2018). This method makes use of robust technologies of oligonucleotide amplification and sequencing, and exploits these oligonucleotide propensities to form a plethora of structures with affinity and specificity for a wide variety of molecules (Stoltenburg et al., 2007; James Cleaves et al., 2011; Sun and $\mathrm{Zu}, 2015)$. These binding affinities can then be explored through the utilization of miniaturized nanopore sequencing and amplification techniques to look for diversity in binding sites. By looking at the diversity of oligonucleotides binding to a sample of interest, and subjecting it to statistical data analyses, we can look for diversity in binding sites that could be reflective of a living, informational system (S.S. Johnson et al., 2019b abstract 5026).

There are many reasons why life, whatever its biochemistry, should be expected to be encapsulated or at least structurally separated from, and thus different from, its environment. As Orgel pointed out, "Molecules that stay together evolve together" (Orgel, 2004), as Darwinian evolution is facilitated by colocalization of informational and functional molecules (Szostak et al., 2001). Therefore, we can make use of established imaging methods in order to look for structural and textural differences within the sample that might indicate some sort of cellular or localized structure, as well as larger structural differences that could signal some sort of organism or ecosystem (or part thereof). These analyses can be done with various microscopic techniques (e.g., holographic, AFM, SEM). Similarly, we can use imaging tools to look for motility, which could represent one of the clearest visible signs of life, especially if the motion is clearly distinguishable from random Brownian motion or motion due to other environmental forces, and especially if the motion seems directed toward an available energy or nutrient source. Vibrational spectroscopy, in particular, was proposed as a method to detect motility (J.C. Johnson et al., 2019 abstract 5079). Motility in combination with a chemical analysis of the putative organism indicating patterns of complexity would be compelling evidence of possible biology.

Another type of biosignature proposed to be agnostic is detection of the presence of an active metabolism or disequilibrium redox reactions inconsistent with abiotic processes. As metabolism is central to biology, it is consistently listed as a highly relevant type of biosignature (Neveu et al., 2018). We can look at active metabolism through consumption/release of compounds (e.g., respirometry) or through changes in energy (e.g., calorimetry and electrochemistry) that are distinct from abiotic oxidation processes (S.S. Johnson et al., 2019b abstract 5026). One example is the use of a redox indicator and infrared thermometry to detect biological activity irrespective of carbon chemistry 
(Koeppel et al., 2019 abstract 5100). Another experiment, though at the time targeted toward only Earth-known biochemistry, was performed on Mars (i.e., Viking Labeled Release experiment) in order to detect the metabolism of radio-labeled carbon substrates. This set of experiments remains the only in situ life-detection effort ever undertaken on another planet (Levin, 2019 abstract 5002).

4.2.3. Earth-like life detection. To look for biosignatures of life on Mars with familiar biochemistry (in other words, life based on the same chemical building blocks and that shares the same heritage to life on Earth), the analysis of the collected data can focus on known chemical or physical signatures that may be detected with space-capable instruments. Some known chemical biosignatures presented and discussed at the meeting include organic biomarkers such as fatty acids (Li et al., 2019 abstract 5027; A.J. Williams et al., 2019 abstract 5016), amino acids (Walker et al., 2019 abstract 5103) or biological gases (K.D. Webster, 2019 abstract 5048), isotopic biosignatures such as sulfur (Mansor et al., 2019 abstract 5018), and inorganic signatures such as manganese minerals (Lanza et al., 2019 abstract 5035) or volatiles (Garvin et al., 2019 abstract 5097). These suites of analyses can potentially be performed using mass spectrometers and spectroscopic instruments that have high heritage in space exploration (Mahaffy et al., 2012; Wiens et al., 2012). Mass spectrometer-based techniques are among the essential tools needed to search for carbon-based biosignatures. Furthermore, gas chromatography-mass spectrometry (GC-MS) aids in the identification of nonpolar compounds, and chemical derivatization coupled with GCMS can even help elucidate more polar compounds such as amino acids (and can quantify the stereochemistry of targeted molecules [Mahaffy et al., 2019 abstract 5022]). Laser desorption ionization-mass spectrometry (LDI-MS) can help mitigate the potential combustion or degradation of organic compounds resulting from pyrolysis techniques amplified by the presence of highly oxidant species on the martian surface ( $\mathrm{Li}$ et al., 2019 abstract 5027). MS/MS, on the other hand, is able to detect and identify organic molecular structures with a large mass range (up to $1000 \mathrm{Da}$ ) (Li et al., 2019 abstract 5027).

Physical biosignatures include macroscopic or microscopic structures that are exhibited by life. For example, stromatolites (microbially influenced sedimentary structures) can contain valuable information about the provenance of such morphological signatures (i.e., the presence of a microbiota) and about the levels of diagenetic and metamorphic changes that the structures experienced (Cady et al., 2003). The Mars 2020 mission will analyze outcrops at Jezero Crater, which was shown to have high preservation potential. Therefore, it is important to understand how structures are made within the geochemical and lithographical context of the depositional environment (Glamoclija et al., 2019 abstract 5041) in order to fully elucidate their potential biogenicity. These structural biosignatures can be analyzed in situ using spectroscopic instruments on board the Mars 2020 rover or other current surface rovers. Microscopic physical biosignatures can range from microfossils to biofilms. Though the biogenicity of ancient Earth microfossils remains controversial (Brasier et al., 2004; Schopf et al., 2007), efforts have been made to enhance detection strategies using Raman spectroscopy (Foucher et al., 2015) and thus have been proposed in space missions as well such as ExoMars 2020. Biofilms, on the other hand, can be detected using microscopy (i.e., SEM) (Spilde et al., 2019 abstract 5036). Fluorescence microscopy combined with microfluidics was also proposed, as it can provide data on the presence of cellular structure, showing not only simple and complex building blocks and information storage molecules (nucleic acids) but also the environmental parameters ( $\mathrm{pH}$, redox potential, conductivity) of the sample matrix (Quinn et al., 2019 abstract 5032).

Another type of biosignature of familiar life is the presence of an active metabolism through direct detection of known metabolites (Benner, 2019 abstract 5112) such as adenosine triphosphate (ATP) (Novak et al., 2019 abstract 5005). Metabolic activity of familiar life could be determined by measuring trace gases such as methane (Allen and Oehler, 2019 abstract 5011; Chen and Yung, 2019 abstract 5061), $\mathrm{H}_{2}, \mathrm{CO}$ (Garvin et al., 2019 abstract 5097) and complex volatile organic compounds (VOCs) (Lee et al., 2019 abstract 5095) respired or consumed by extant life. The uptake of labeled isotopes $(\mathrm{C}, \mathrm{N}, \mathrm{S})$ such as in the Viking Labeled Release experiment can provide data on metabolic activity and the enantiomer ratio (chirality) of the sample (Levin, 2019 abstract 5002; Mackelprang et al., 2019 abstract 5015; Mardon et al., 2019 abstract 5071). Finally, it is important to note that the definitiveness of these results would be dependent on our ability to distinguish signals from noise and would depend on individual results within the context of the entirety of the results.

4.2.4. Concepts for Mars Sample Return. Conference attendees agreed that we would be able to detect extant life in a sample return mission using modern biological techniques with the suite of instruments at our disposal on Earth-if the life-forms present were based on Earth biogeochemistry (Fig. 10). This is based on the assumption that the collected sample has been returned without getting contaminated during collection or transportation. Meanwhile, it is important to note that if the life-form were based on another biochemistry, modern techniques might be too specific. We determined that using a well-designed suite of multiple advanced detection techniques, which provide complementary information for life detection, would be especially important. The advantage of a return mission would thus be in the ability to access a multitude of more sensitive instruments and wide-ranging laboratory techniques than is possible for in situ missions. We agreed that life-detection instrument development programs should be a priority and that more research should be conducted to understand what signals of life may be universal and how to best detect those.

4.2.5. Summary. Once a promising environment for searching for extant life is selected for exploration using the strategies described in Section 4.1 and a mission is selected to be sent there, the next step would be target selection and analysis. The first phase of analyses could be to determine molecular composition, including the complexity, abundance, isotopic composition, and chirality of the compounds present. The second step of data collection could then be focused on the structure and texture of the sample, morphology, the potential presence of cellular structures or 


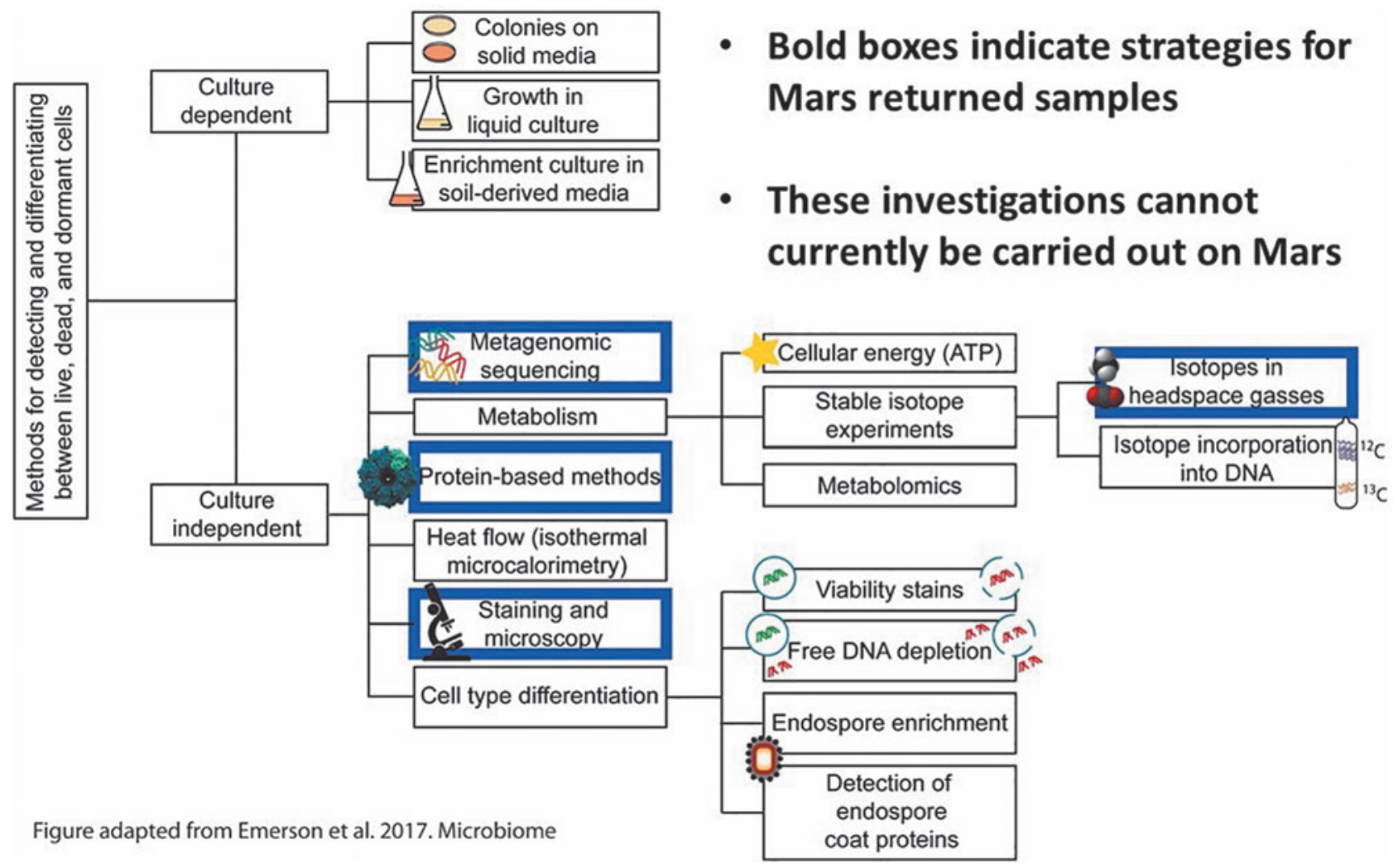

FIG. 10. Summary of methods commonly used in terrestrial samples for detecting live, dead, and dormant cells-all of these could be applied to the problem of Mars extant life detection. Note that some of the key measurements on this figure are not currently possible at Mars and would require Mars Sample Return. Shown by Mackelprang et al. (2019 abstract 5015) at the conference.

motility. A subsequent set of data collection could be used look for the presence of an active metabolism through consumption/release of compounds (e.g., respirometry), through changes in energy utilization (e.g., calorimetry and electrochemistry), or disequilibrium redox reactions inconsistent with abiotic processes. The definitiveness of these results would be dependent on our ability to distinguish signals from noise and would depend on individual results within the context of the entirety of the results.

Future missions would therefore benefit from the development of instruments capable of direct and unambiguous detection of extant life in situ, and improvements are needed in capabilities for sample preparation to optimize biosignature detection. Spacecraft resources should support a sufficient number of sample analyses to support replicate analyses, positive and negative controls. Contamination control should be coupled with contamination knowledge so that Earth-sourced material can be eliminated as a possible source of any biological material discovered in martian samples.

\subsection{Possible constraints relevant to the search for extant martian life derived from laboratory experiments}

4.3.1. Overview. Laboratory simulations to constrain the search for martian extant life are interdisciplinary research endeavors involving biologists, chemists, geologists, planetary scientists, and physicists. On Earth, simulation facilities and chambers have been built to mimic martian surface and subsurface conditions (see, e.g., Fig. 11), enabling studies into potential microbiology, biosignature detection, degradation of organics, geochemical processes, and instrumentation tests (see reviews by Fairén et al., 2010; Olsson-Francis and Cockell, 2010; Rabbow et al., 2016; Schwendner and Schuerger, 2020). Mars simulators have ranged from small low-cost desiccators connected to pumps and controllers (e.g., Schuerger et al., 2013; Fig. 11A and $11 \mathrm{~B})$, to mid-sized chambers composed of stainless steel vessels simulating up to five concomitant environmental stressors (e.g., ten Kate et al., 2002; Schuerger et al., 2008; Fischer et al., 2014; Martin and Cockell, 2015; dos Santos et al., 2016; Fig. 11C), and up to large complex systems (e.g., Sears et al., 2002; Rabbow et al., 2016). Martian conditions have also been simulated by wind tunnels and tumbling carousels that mimic saltation processes, while analog terrestrial habitats, including Earth's stratosphere, provide important links between lab experiments and models (Olsson-Francis and Cockell, 2010; Rabbow et al., 2016; P. DasSarma and DasSarma, 2018). These topics were discussed in a number of papers given at the conference (Glamoclija et al., 2019 abstract 5041; Kring, 2019 abstract 5081; LaJoie et al., 2019 abstract 5051; Novak et al., 2019 abstract 5005; Viola and McKay, 2019 abstract 5099).

4.3.2. Constraints on conducting Mars simulations. Even with the best Mars simulators, there are no "perfect" lab 
FIG. 11. Mars simulators can be relatively simple with low-cost controllers (A) or connected to polycarbonate desiccators (B) (see Schwendner and Schuerger, 2019 abstract 5006). In contrast, more complicated Mars simulators (C; from Schuerger and Britt, 2019 abstract 5004; Schuerger et al., 2008) are generally required to simulate additional environmental parameters (e.g., UV flux on Mars) while concomitantly holding low temperature, low pressure, and $\mathrm{CO}_{2}$-enriched hypoxic conditions. All simulators have caveats on what and how to recreate surface conditions on Mars, but simulation experiments are essential to close the knowledge gaps among analog research, planetary missions, and habitability models.
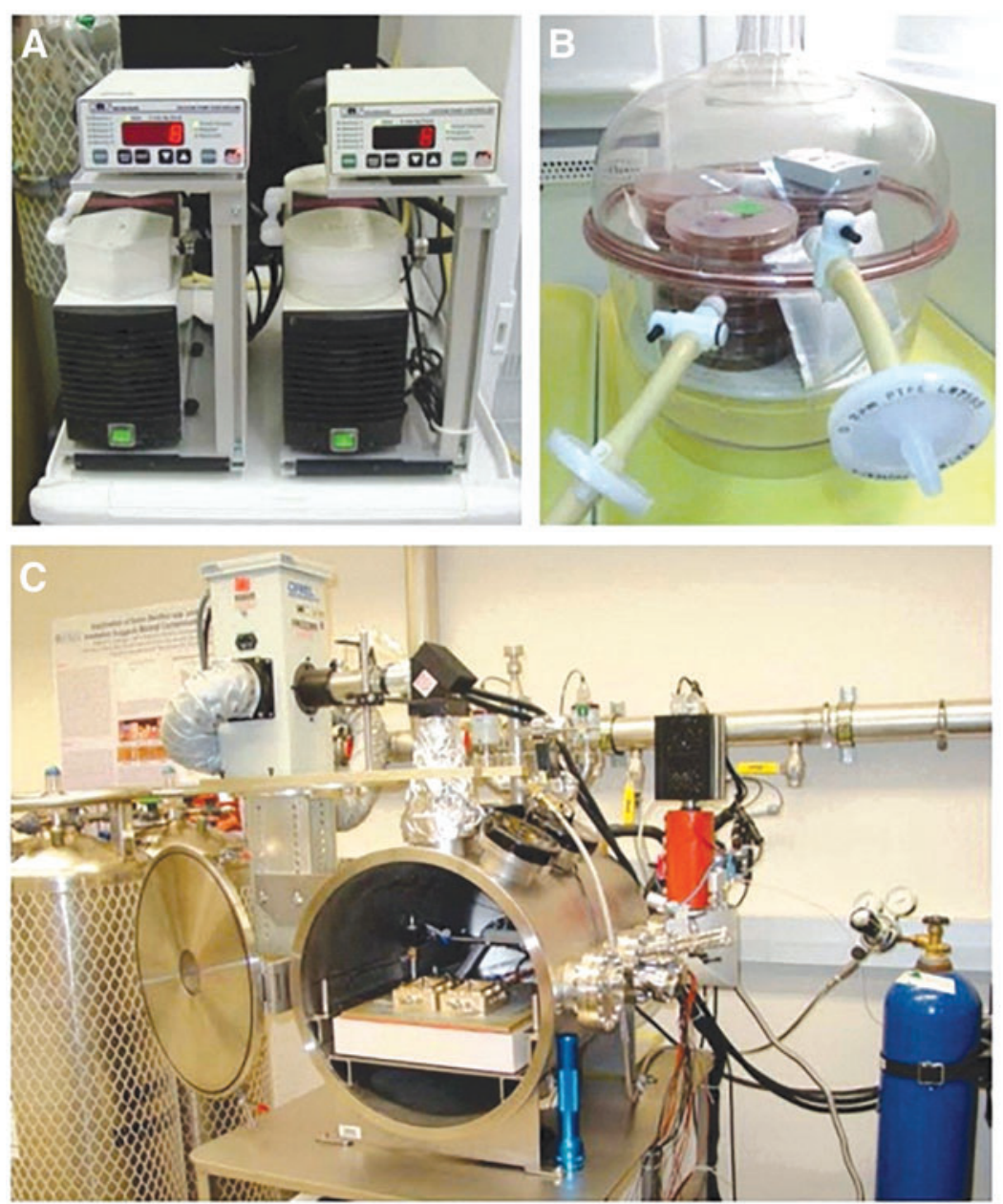

simulations; all such experiments have inherent caveats and can only recreate a subset of the conditions present on Mars. For example, several recent papers on the habitability of Mars (Beaty et al., 2006; Fairén et al., 2010; Stoker et al., 2010; Rummel et al., 2014; Cockell et al., 2016) have identified up to 22 biocidal stressors on the surface or shallow subsurface. Testing all possible combinations of these factors is not possible now or any time in the futurethat is, $22 !=10^{21}$ possible treatment combinations, which are not falsifiable in the extreme as an aggregate. In fact, even testing all possible combinations of four or five factors can be very problematic (i.e., $4 !=24$ combinations; $5 !=120$ combinations). Furthermore, searching for life on Mars is inherently biased by our understanding of life's evolution and ecology on Earth (Schulze-Makuch et al., 2013; Cabrol, 2018; and see Wade and Lenski, 2019 abstract 5053). However, prebiotic chemistry experiments may inform our understanding of possible forms of extinct or extant martian life (Gasda et al., 2019 abstract 5034; Hoog et al., 2019 abstract 5098), as well as environments that could support the emergence of life (Ricardo et al., 2004; Stephenson et al., 2013).

Although lab simulations have inherent caveats-like all experiments and models-lab studies with Mars simulators will remain key components for the search for life on Mars for several reasons. First, lab simulations allow empirical and theoretical linkage among Earth analog sites, Mars in situ sites, thermodynamics, geochemistry, hydrology, and biology without requiring a physical presence on Mars. Until biological research labs are built on Mars, Earth lab simulations combined with fieldwork in extreme environments will be our best means of investigating possible constraints on extant martian life. Second, lab simulators are required because many environmental conditions on Mars do not naturally occur on Earth. For example, the atmospheric pressures on Earth and Mars range between $33 \mathrm{kPa}$ (peak of Mt. Everest) to $101.3 \mathrm{kPa}$ (sea level) compared to $0.2 \mathrm{kPa}$ (peak of Mt. Olympus) to $1.2 \mathrm{kPa}$ (bottom of Hellas Basin), respectively. Such low pressures for Mars only exist on Earth in the middle stratosphere at an altitude of 30$50 \mathrm{~km}$ (Schuerger and Nicholson, 2016). Other diverse conditions present on Mars that are not typically encountered on Earth are UV irradiation between 190 and $300 \mathrm{~nm}$, increased ionizing radiation from galactic sources and solar output, a $\mathrm{CO}_{2}$-dominant hypoxic gas mixture, extremes in desiccation, high salts, extreme low temperatures, and volatile oxidants (Olsson-Francis and Cockell, 2010; Rabbow et al., 2016; Rowe et al., 2019 abstract 5010; Schwendner and Schuerger, 2020). Third, in order to combine geochemistry, thermodynamics of liquid water, and biology in future life-detection instruments, lab experiments under Mars-relevant conditions cannot be easily designed without 
appropriate simulators. And lastly, experimental data from simulators, martian soil simulants, and analog sites are required to populate and validate models, and are essential to developing life-detection instruments (Koeppel et al., 2019 abstract 5100; Tarasashvili and Aleksidze, 2019 abstract 5014; Walker et al., 2019 abstract 5103).

4.3.3. Lessons learned from lab simulations. Several discoveries derived from Earth-based and space-based Mars studies have led to potential guiding tenets to follow when searching for an extant microbial community on Mars. The biocidal and inhibitory stressors on the surface of Mars are generally perceived to be extreme enough that they may prevent the persistence of extant life at the surface (Schwendner and Schuerger, 2019 abstract 5006). First, almost all UV-irradiation assays conducted under diverse simulated martian conditions support the conclusion that Earth microorganisms may not have evolved protective features that grant immunity to solar UV irradiation (e.g., see reviews by Nicholson et al., 2000; Horneck et al., 2010; Schwendner and Schuerger, 2020) and that an extant microbiota might fall under a similar range of sensitivity as found for terrestrial life. Only UV-protected niches offer adequate shielding to allow adaptation to the martian surface, which could be achieved with just a few millimeters of overlying regolith (Rummel et al., 2014). Water activity $\left(a_{\mathrm{w}}\right)<0.61$ is the second dominant biocidal stressor on the surface of Mars that could prevent microbial replication (Rummel et al., 2014). However, inadequate work has been conducted to completely rule out the presence of higher $a_{\mathrm{w}}$ (i.e., 0.61-1.0) in microniches in rocks or regolith at the surface of Mars. And third, low-pressure (0.2-1.2 kPa), oligotrophic conditions of the regolith, a $\mathrm{CO}_{2}$-enriched hypoxic atmosphere, high salts, and generally low temperatures on the surface of Mars suggest that if extant martian life is present it will be pushed to the limits of growth also observed for many extremophilic species and communities on Earth. Thus, given these and other extremes (see above) at the surface of Mars, the collective body of experimental data would seem to imply that shallow subsurface locations (at least $1-10 \mathrm{~m}$ deep) and deeper subterranean niches (e.g., caves, buried ices and salts, and deep regolith) may be the best locations to search for an extant microbiota on Mars.

\section{Discussion}

Conference discussions were carried out at multiple levels. These involved (A) Short presentation-level discussions at the end of each oral talk; (B) Somewhat longer sessionlevel discussions after each session, which allowed the papers in a given session to be compared and contrasted; (C) Theme-based small-group discussion/integration processes, which resulted in consolidated messages from oral, poster, and print-only abstracts; and (D) Presentation and discussion of the consolidated messages in the conference's concluding session. Based on these discussions, the following consensus positions were developed:

(1) A significant subset of the actively publishing Mars science community who are experts in various disciplines of relevance to interpreting habitability and astrobiology concluded that there exists a realistic possibility that Mars hosts indigenous microbial life and that there are testable hypotheses for seeking it. As such, the conference participants concluded that the search for extant life on Mars remains an important scientific objective.

(2) A powerful theme that permeated the conference is that the key to the search for martian extant life lies in identifying and exploring refugia (i.e., "oases"), where conditions are either permanently or episodically significantly more hospitable than average, that is, the "Refugium Model." Martian life, if it was once more widespread, could have retreated to one or more of these refugia, where it may have been able to survive long-term.

(3) Based on our existing knowledge of Mars, four martian environments were highlighted during the course of the conference as having the potential to be such refugia. For each of these, multiple advocates were present at the conference.
(a) Caves
(b) Deep subsurface sites
(c) Ices
(d) Salts

We are aware that other possible refugia have been hypothesized in the literature (e.g., recurring slope lineae), but they were not discussed at this conference.

(4) The conference group did not attempt to reach a consensus prioritization of these candidate environments. There are multiple considerations that would go into such an evaluation, including overall potential for a discovery of life, the difficulty of accessing the environments, and the potential issues with performing conclusive measurements. The group was most comfortable with prioritizing these options by means of a future competitive process involving mission proposals.

(5) There is an important implication of the "Refugia Model": If environments exist where conditions are significantly better than average, there must also be complementary environments where conditions are significantly worse than average. One example of the latter might be the surface and very shallow subsurface regolith on Mars. It is recognized, however, that we cannot reach definitive conclusions about what conditions would be truly inhospitable for martian life until we discover it and measure its properties.

(6) Geological strategies to search for biosignatures could potentially be used to help identify locations with the best probability of detecting extant life, sites in which extant life is currently absent but was present in the recent past, and sites containing traces of extant life delivered from elsewhere. "Geological" biosignatures include certain organic and inorganic compounds, minerals, sedimentary structures, morphologies, textures, and stable isotopic patterns. The temporal and spatial distribution of any biosignatures of extant life may be highly heterogeneous due to the processes that control habitability and preservation. A key challenge is to identify and visit sites where any biosignatures are both accessible and sufficiently abundant to be detectible. If the origin of biosignatures can be confirmed as geologically recent, then they probably indicate that life still exists somewhere. 
(7) A number of different measurement techniques to detect evidence of extant life (if present) have been proposed. Again, it was not within the scope of this conference to prioritize these measurement techniques - that is best left for the competitive process. One important note: The number and sensitivities of detection methods that could be implemented if samples were returned to Earth greatly exceed the methodologies that could be used on Mars.

(8) Important lessons to guide extant life search processes can be derived both from experiments carried out in terrestrial laboratories and on terrestrial analogs and from theoretical modelling.

(9) If the habitability potential for extant martian life (and transported terrestrial microbial life) at the martian equatorial surface is very low, this fact should be factored into interpretations of forward and backward planetary protection risks for future missions to those regions. This may specifically have implications for how to manage the risks associated with future human missions to Mars. We encourage further experimentation on the limits of life relevant to surface conditions on Mars in order to advance the discussions of the search for extant life on Mars.

\section{Acknowledgments}

Shiladitya DasSarma acknowledges support by NASA grant 80NSSC19K0463. Peter Lee acknowledges support from NASA grant 80NSSC17K0243 and NSF grant OCE1428915. Andrew Schuerger and Petra Schwendner recognize support from a NASA Planetary Protection Research program grant (80NSSC17K0263).

A portion of this work was carried out at the Jet Propulsion Laboratory, California Institute of Technology, under a contract from the National Aeronautics and Space Administration (80NM0018D0004). U.S. Government sponsorship is acknowledged.

Any information about mission concepts discussed in this document is predecisional and is provided for planning and discussion only.

\section{References}

Allen, C.C. and Oehler, D.Z. (2019) Searching for martian bioindicators and extant life using spacecraft [abstract 5011]. In Mars Extant Life: What's Next? Conference Abstracts, Lunar and Planetary Institute, Houston. Available online at https:// www.hou.usra.edu/meetings/lifeonmars2019/pdf/5011.pdf

Allwood, A., Clark, B., Flannery, D., Hurowitz, J., Wade, L., Elam, T., Foote, M., and Knowles, E. (2015) Texture-specific elemental analysis of rocks and soils with PIXL: the Planetary Instrument for X-ray Lithochemistry on Mars 2020. In 2015 IEEE Aerospace Conference, IEEE, Piscataway, NJ, doi:10.1109/AERO.2015.7119099.

Bakermans, C. and Whyte, L.G. (2019) Terrestrial permafrost as a model for microbial growth at low temperatures: implications for extant life [abstract 5040]. In Mars Extant Life: What's Next? Conference Abstracts, Lunar and Planetary Institute, Houston. Available online at https://www.hou.usra.edu/ meetings/lifeonmars2019/pdf/5040.pdf

Bar-Cohen, Y., Sherrit, S., Badescu, M., Lee, H.J., Bao, X., and Chang, Z. (2018) Drilling mechanisms using piezoelectric actuators developed at Jet Propulsion Laboratory. In Outer Solar System: Prospective Energy and Material Resources, Springer International Publishing, Cham, Switzerland, pp 181-259.

Beaty, D.W., Buxbaum, K.L., Meyer, M.A., Barlow, N., Boynton, W., Clark, B., Deming, J., Doran, P.T., Edgett, K., Hancock, S., Head, J., Hecht, M., Hipkin, V., Kieft, T., Mancinelli, R., McDonald, E., McKay, C., Mellon, M., Newsom, H., Ori, G., Paige, D., Schuerger, A.C., Sogin, M., Spry, J.A., Steele, A., Tanaka, K., and Voytek, M. (2006) Findings of the Mars Special Regions Science Analysis Group. Astrobiology 6:677732.

Benner, S.A. (2019) Detecting extant life on Mars. An instrument design that avoids guesswork [abstract 5112]. In Mars Extant Life: What's Next? Conference Abstracts, Lunar and Planetary Institute, Houston. Available online at https:// www.hou.usra.edu/meetings/lifeonmars2019/pdf/5112.pdf

Bidle, K.D., Lee, S., Marchant, D.R., and Falkowski, P.G. (2007) Fossil genes and microbes in the oldest ice on earth. Proc Natl Acad Sci USA 104:13455-13460.

Blank, J.G. (2019) Remote and in situ characterization of microbial life and the geochemical record of life in terrestrial lava tubes, analogs for martian volcanic caves [abstract 5108]. In Mars Extant Life: What's Next? Conference Abstracts, Lunar and Planetary Institute, Houston. Available online at https://www.hou.usra.edu/meetings/lifeonmars2019/ pdf/5108.pdf

Blank, J.G., Colaprete, A., Datta, S., Deans, M., Fong, T., Léveillé, R.L., Michael, N., Northup, D.E., Parness, A., Roush, T.L., Skok, J.R., Stoker, C.L., Whittaker, R., Wong, U., and Wynne, J.J. (2018) Planetary Caves as Astrobiology Targets, white paper submitted to the Space Studies Board of the National Academy of Sciences. Available online at https:// sites.nationalacademies.org/cs/groups/ssbsite/documents/ webpage/ssb_190758.pdf

Boston, P.J., Spilde, M.N., Northup, D.E., Melim, L.A., Soroka, D.S., Kleina, L.G., Lavoie, K.H., Hose, L.D., Mallory, L.M., Dahm, C.N., Crossey, L.J., and Schelble, R.T. (2001) Cave biosignature suites: microbes, minerals, and Mars. Astrobiology 1:25-55.

Boston, P.J., Northup, D.N., and Spilde, M.N. (2019) Longduration natural storage of viable organisms in geological materials and structures as a model for obliquity over-wintering on Mars [abstract 5058]. In Mars Extant Life: What's Next? Conference Abstracts, Lunar and Planetary Institute, Houston. Available online at https://www.hou.usra.edu/meetings/ lifeonmars2019/pdf/5058.pdf

Brasier, M.D., Green, O.R., and Mcloughlin, N. (2004) Characterization and critical testing of potential microfossils from the early Earth: the Apex 'microfossil debate' and its lessons for Mars sample return. Int J Astrobiol 3:139-150.

Byrne, S., Dundas, C.M., Kennedy, M.R., Mellon, M.T., McEwen, A.S., Cull, S.C., Daubar, I.J., Shean, D.E., Seelos, K.D., Murchie, S.L., Cantor, B.A., Arvidson, R.E., Edgett, K.S., Reufer, A., Thomas, N., Harrison, T.N., Posiolova, L.V., and Seelos, F.P. (2009) Distribution of mid-latitude ground ice on Mars from new impact craters. Science 325:1674-1676.

Cabrol, N.A. (2018) The coevolution of life and environment on Mars: an ecosystem perspective on the robotic exploration of biosignatures. Astrobiology 18:1-27.

Cady, S.L., Farmer, J.D., Grotzinger, J.P., Schopf, J.W., and Steele, A. (2003) Morphological biosignatures and the search for life on Mars. Astrobiology 3:351-368.

Carr, M.H. (1987) Water on Mars. Nature 326:30-35. 
Chen, P. and Yung, Y.L. (2019) Possible uptake of Mars atmospheric gases by an extant biosphere [abstract 5061]. In Mars Extant Life: What's Next? Conference Abstracts, Lunar and Planetary Institute, Houston. Available online at https:// www.hou.usra.edu/meetings/lifeonmars2019/pdf/5061.pdf

Chevrier, V.F. and Altheide, T.S. (2008) Low temperature aqueous ferric sulfate solutions on the surface of Mars. Geophys Res Lett 35:L22101.

Chevrier, V.F., Hanley, J., and Altheide, T.S. (2009) Stability of perchlorate hydrates and their liquid solutions at the Phoenix landing site, Mars. Geophys Res Lett 36:L10202.

Chivian, D., Brodie, E.L., Alm, E.J., Culley, D.E., Dehal, P.S., DeSantis, T.Z., Gihring, T.M., Lapidus, A., Lin, L.H., Lowry, S.R., Moser, D.P., Richardson, P.M., Southam, G., Wanger, G., Pratt, L.M., Andersen, G.L., Hazen, T.C., Brockman, F.J., Arkin, A.P., and Onstott, T.C. (2008) Environmental genomics reveals a single-species ecosystem deep within Earth. Science 322:275-278.

Clark, B.C. and Kolb, V.M. (2019) Why life should have started on Mars, and searching for survivors in salts [abstract 5008]. In Mars Extant Life: What's Next? Conference Abstracts, Lunar and Planetary Institute, Houston. Available online at https:// www.hou.usra.edu/meetings/lifeonmars2019/pdf/5008.pdf

Clark, B.C. and Kounaves, S.P. (2016) Evidence for the distribution of perchlorates on Mars. Int J Astrobiol 15:311318.

Cockell, C.S., Bush, T., Bryce, C., Direito, S., Fox-Powell, M., Harrison, J.P., Lammer, H., Landenmark, H., Martin-Torres, J., Nicholson, N., Noack, L., O’Malley-James, J., Payler, S.J., Rushby, A., Samuels, T., Schwendner, P., Wadsworth, J., and Zorzano, M.P. (2016) Habitability: a review. Astrobiology 16: 89-117.

Collins, M.A. and Buick, R.K. (1989) Effect of temperature on the spoilage of stored peas by Rhodotorula glutinis. Food Microbiol 6:135-141.

Connon, S.A., Lester, E.D., Shafaat, H.S., Obenhuber, D.C., and Ponce, A. (2007) Bacterial diversity in hyperarid Atacama desert soils. J Geophys Res Biogeosciences 112, doi:10.1029/ 2006JG000311.

Crossey, L.J., Karlstrom, K.E., Schmandt, B., Crow, R.R., Colman, D.R., Cron, B., Takacs-Vesbach, C.D., Dahm, C.N., Northup, D.E., Hilton, D.R., Ricketts, J.W., and Lowry, A.R. (2016) Continental smokers couple mantle degassing and distinctive microbiology within continents. Earth Planet Sci Lett 435:22-30.

Cushing, G. (2012) Candidate cave entrances on Mars. J Caves Karst Stud 74:33-47.

Cushing, G.E. (2017) Mars Global Cave Candidate Catalog (MGC3) [abstract 3708]. In Astrobiology Science Conference, Lunar and Planetary Institute, Houston. Available online at https://www.hou.usra.edu/meetings/abscicon2017/ pdf/3708.pdf

Cushing, G.E. and Okubo, C.H. (2016) Description of the Mars Global Cave Candidate Catalog (MGC3), United States Geological Service. Available online at https://astrogeology.usgs.gov/ search/map/Mars/MarsCaveCatalog/mars_cave_catalog

Cushing, G.E., Titus, T.N., Wynne, J.J., and Christensen, P.R. (2007) THEMIS observes possible cave skylights on Mars. Geophys Res Lett 34, doi:10.1029/2007GL030709.

DasSarma, S. and Arora, P. (2017) Halophiles. In Encyclopedia of Life Sciences, John Wiley and Sons, New York.

DasSarma, P. and DasSarma, S. (2018) Survival of microbes in Earth's stratosphere. Curr Opin Microbiol 43, doi:10.1016/ j.mib.2017.11.002.
DasSarma, S. and DasSarma, P. (2019) The green edge: haloarchaeal photopigments as biosignatures for detection of extant life on Mars [abstract 5092]. In Mars Extant Life: What's Next? Conference Abstracts, Lunar and Planetary Institute, Houston. Available online at https://www.hou.usra.edu/ meetings/lifeonmars2019/pdf/5092.pdf

DasSarma, S., DasSarma, P., Laye, V.J., and Schwieterman, E.W. (2019) Extremophilic models for astrobiology: haloarchaeal survival strategies and pigments for remote sensing. Extremophiles 24, doi:10.1007/s00792-019-01126-3.

Davila, A.F. and Schulze-Makuch, D. (2016) The last possible outposts for life on Mars. Astrobiology 16:159-168.

Davila, A.F., Duport, L.G., Melchiorri, R., Jänchen, J., Valea, S., de los Rios, A., Fairén, A.G., Möhlmann, D., McKay, C.P., Ascaso, C., and Wierzchos, J. (2010) Hygroscopic salts and the potential for life on Mars. Astrobiology 10:617-628.

Davila, A.F., Kahre, M.A., Quinn, R.C., and Des Marais, D.J. (2019) The biological potential of present-day Mars. In Planetary Astrobiology, edited by V. Meadows, The University of Arizona Space Science Series, University of Arizona, Tucson, AZ.

Des Marais, D.J. (2001) Isotopic evolution of the biogeochemical carbon cycle during the Precambrian. Rev Mineral Geochem 43:555-578.

Des Marais, D.J. (2019a) Biosignatures of past life are also relevant to the search for extant life [abstract 5023]. In Mars Extant Life: What's Next? Conference Abstracts, Lunar and Planetary Institute, Houston. Available online at https:// www.hou.usra.edu/meetings/lifeonmars2019/pdf/5023.pdf

Des Marais, D.J. (2019b) Isotopic evolution of the biogeochemical carbon cycle during the Precambrian. In Stable Isotope Geochemistry, Vol. 43, De Gruyter Mouton, Boston, MA, pp 555-578.

Des Marais, D.J. and Jahnke, L.L. (2019) Biosignatures of cellular components and metabolic activity. In Advances in Astrobiology and Biogeophysics, Springer Verlag, Berlin, pp 51-85.

dos Santos, R., Patel, M., Cuadros, J., and Martins, Z. (2016) Influence of mineralogy on the preservation of amino acids under simulated Mars conditions. Icarus 277:342-353.

Dundas, C.M., Bramson, A.M., Ojha, L., Wray, J.J., Mellon, M.T., Byrne, S., McEwen, A.S., Putzig, N.E., Viola, D., Sutton, S., Clark, E., and Holt, J.W. (2018) Exposed subsurface ice sheets in the martian mid-latitudes. Science 359: 199-201.

Dutta, A., Dutta Gupta, S., Gupta, A., Sarkar, J., Roy, S., Mukherjee, A., and Sar, P. (2018) Exploration of deep terrestrial subsurface microbiome in Late Cretaceous Deccan traps and underlying Archean basement, India. Sci Rep 8:1-16.

Ehlmann, B.L. and Edwards, C.S. (2014) Mineralogy of the martian surface. Annu Rev Earth Planet Sci 42:291-315.

Eigenbrode, J.L., Glass, B., McKay, C.P., Niles, P., and Spry, J.A. (2019) Martian subsurface ice science investigation [abstract 5020]. In Mars Extant Life: What's Next? Conference Abstracts, Lunar and Planetary Institute, Houston. Available online at https://www.hou.usra.edu/meetings/lifeonmars2019/ pdf/5020.pdf

Elaksher, A.F. (2019) Reliable Mars topographic surfaces for future landing sites [abstract 5094]. In Mars Extant Life: What's Next? Conference Abstracts, Lunar and Planetary Institute, Houston. Available online at https://www.hou.usra.edu/meetings/ lifeonmars2019/pdf/5094.pdf

Emerson, J.B., Adams, R.I., Román, C.M.B., Brooks, B., Coil, D.A., Dahlhausen, K., Ganz, H.H., Hartmann, E.M., Hsu, T., 
Justice, N.B., Paulino-Lima, I.G., Luongo, J.C., Lymperopoulou, D.S., Gomez-Silvan, C., Rothschild-Mancinelli, B., Balk, M., Huttenhower, C., Nocker, A., Vaishampayan, P., and Rothschild, L.J. (2017). Schrödinger's microbes: tools for distinguishing the living from the dead in microbial ecosystems. Microbiome 5, doi:10.1186/s40168-017-0285-3.

Eshelman, E.J., Malaska, M.J., Manatt, K.S., Doloboff, I.J., Wanger, G., Willis, M.C., Abbey, W.J., Beegle, L.W., Priscu, J.C., and Bhartia, R. (2019) WATSON: in situ organic detection in subsurface ice using deep-UV fluorescence spectroscopy. Astrobiology 19:771-784.

Fairén, A.G., Davila, A.F., Lim, D., Bramall, N., Bonaccorsi, R., Zavaleta, J., Uceda, E.R., Stoker, C., Wierzchos, J., Dohm, J.M., Amils, R., Andersen, D., and McKay, C.P. (2010) Astrobiology through the ages of Mars: the study of terrestrial analogues to understand the habitability of Mars. Astrobiology 10:821-843.

Farmer, J.D. (1999) Taphonomic modes in microbial fossilization. In Size Limits of Very Small Microorganisms: Proceedings of a Workshop, National Academies Press, Washington, DC, pp 94-102.

Feldman, W.C., Prettyman, T.H., Maurice, S., Plaut, J.J., Bish, D.L., Vaniman, D.T., Mellon, M.T., Metzger, A.E., Squyres, S.W., Karunatillake, S., Boynton, W.V., Elphic, R.C., Funsten, H.O., Lawrence, D.J., and Tokar, R.L. (2004) Global distribution of near-surface hydrogen on Mars. J Geophys Res 109, doi:10.1029/2003JE002160.

Fischer, E., Martínez, G.M., Elliott, H.M., and Rennó, N.O. (2014) Experimental evidence for the formation of liquid saline water on Mars. Geophys Res Lett 41:4456-4462.

Ford, D. and Williams, P. (2013) Karst Hydrogeology and Geomorphology, John Wiley and Sons, Hoboken, NJ.

Foucher, F., Ammar, M.-R., and Westall, F. (2015) Revealing the biotic origin of silicified Precambrian carbonaceous microstructures using Raman spectroscopic mapping, a potential method for the detection of microfossils on Mars. J Raman Spectrosc 46:873-879.

Garvin, Z.K., Abades, S.R., Trefault, N., Alfaro, F.D., and Onstott, T.C. (2019) High-affinity trace gas consumption by soil microbial communities around hot springs in the Andean Altiplano: implications for the evolution of martian metabolisms [abstract 5097]. In Mars Extant Life: What's Next? Conference Abstracts, Lunar and Planetary Institute, Houston. Available online at https://www.hou.usra.edu/meetings/ lifeonmars2019/pdf/5097.pdf

Gasda, P.J., Parsons, B., Nellessen, M.A., Crossey, L., Peterson, E., Lanza, N.L., Yeager, C., Labrouriau, A., Wiens, R.C., and Clegg, S. (2019) Prebiotic chemistry of boratebearing clays: a potential Mars biosignature [abstract 5034]. In Mars Extant Life: What's Next? Conference Abstracts, Lunar and Planetary Institute, Houston. Available online at https:// www.hou.usra.edu/meetings/lifeonmars2019/pdf/5034.pdf

Georgiou, C.D., Zisimopoulos, D., Kalaitzopoulou, E., and Quinn, R.C. (2017) Radiation-driven formation of reactive oxygen species in oxychlorine-containing Mars surface analogues. Astrobiology 17:319-336.

Getty, S.A. (2018) Life Detection Instrumentation in a Golden Age of Astrobiology, NASA Goddard Space Flight Center, Greenbelt, MD. Presentation to the National Academies of Sciences, Engineering, and Medicine. Available online at https:// sites.nationalacademies.org/cs/groups/ssbsite/documents/web page/ssb_185648.pdf

Gillieson, D. (2009) Caves: Processes, Development and Management, Wiley Blackwell, Oxford.
Glamoclija, M., Murphy, A., Taj-Eddine, K., and Ori, G.G. (2019) Biosignatures in Precambrian and Cambrian carbonate rich sedimentary sequences of Anti-Atlas, Morocco [abstract 5041]. In Mars Extant Life: What's Next? Conference Abstracts, Lunar and Planetary Institute, Houston. Available online at https://www.hou.usra.edu/meetings/lifeonmars2019/ pdf/5041.pdf

Goossens, S., Sabaka, T.J., Genova, A., Mazarico, E., Nicholas, J.B., and Neumann, G.A. (2017) Evidence for a low bulk crustal density for Mars from gravity and topography. Geophys Res Lett 44:7686-7694.

Grimm, R.E., Harrison, K.P., Stillman, D.E., and Kirchoff, M.R. (2017) On the secular retention of ground water and ice on Mars. J Geophys Res Planets 122:94-109.

Harris, R.L., Ehlmann, B.L., Bhartia, R., and Onstott, T.C. (2019) Biologically mediated anaerobic methane oxidationthe missing sink in an active martian methane cycle? [abstract 5050]. In Mars Extant Life: What's Next? Conference Abstracts, Lunar and Planetary Institute, Houston. Available online at https://www.hou.usra.edu/meetings/lifeonmars2019/ pdf/5050.pdf

Hays, L.E., Graham, H.V., Des Marais, D.J., Hausrath, E.M., Horgan, B., McCollom, T.M., Parenteau, M.N., Potter-McIntyre, S.L., Williams, A.J., and Lynch, K.L. (2017) Biosignature preservation and detection in Mars analog environments. Astrobiology 17:363-400.

Hazen, R.M., Papineau, D., Bleeker, W., Downs, R.T., Ferry, J.M., McCoy, T.J., Sverjensky, D.A., and Yang, H. (2008) Mineral evolution. Am Mineral 93:1693-1720.

Heard, A.W., Warr, O., Borgonie, G., Linage, B., Kuloyo, O., Fellowes, J.W., Magnabosco, C., Lau, M.C.Y., Erasmus, M., Cason, E.D., van Heerden, E., Kieft, T.L., Mabry, J.C., Onstott, T.C., Sherwood Lollar, B., and Ballentine, C.J. (2018) South African crustal fracture fluids preserve paleometeoric water signatures for up to tens of millions of years. Chem Geol 493:379-395.

Holt, R.M. and Powers, D.W. (2019) Halite, extant life, Permian Salado formation, and Mars [abstract 5046]. In Mars Extant Life: What's Next? Conference Abstracts, Lunar and Planetary Institute, Houston. Available online at https:// www.hou.usra.edu/meetings/lifeonmars2019/pdf/5046.pdf

Hoog, T., Gaut, N., Pawlak, M.R., Bachan, B.F., and Engelhart, A.E. (2019) Mars as a prebiotic chemistry laboratory: a martian RNA world? [abstract 5098]. In Mars Extant Life: What's Next? Conference Abstracts, Lunar and Planetary Institute, Houston. Available online at https://www.hou.usra.edu/ meetings/lifeonmars2019/pdf/5098.pdf

Horneck, G., Klaus, D.M., and Mancinelli, R.L. (2010) Space microbiology. Microbiol Mol Biol Rev 74:121-156.

Horowitz, N.H., Hobby, G.L., and Hubbard, J.S. (1976) The Viking carbon assimilation experiments: interim report. Science 194:1321-1322.

Horowitz, N.H., Hobby, G.L., and Hubbard, J.S. (1977) Viking on Mars: the carbon assimilation experiments. J Geophys Res $82: 4659-4662$.

Houtkoope, J.M. and Schulze-Makuch, D. (2007) A possible biogenic origin for hydrogen peroxide on Mars: the Viking results reinterpreted. Int J Astrobiol 6:147-152.

Huguenin, R.L. (1982) Chemical weathering and the Viking Biology Experiments on Mars. J Geophys Res 87, doi: 10.1029/jb087ib12p10069.

Inagaki, F., Hinrichs, K.U., Kubo, Y., Bowles, M.W., Heuer, V.B., Hong, W.L., Hoshino, T., Ijiri, A., Imachi, H., Ito, M., Kaneko, M., Lever, M.A., Lin, Y.S., Methé, B.A., Morita, S., 
Morono, Y., Tanikawa, W., Bihan, M., Bowden, S.A., Elvert, M., Glombitza, C., Gross, D., Harrington, G.J., Hori, T., Li, K., Limmer, D., Liu, C.H., Murayama, M., Ohkouchi, N., Ono, S., Park, Y.S., Phillips, S.C., Prieto-Mollar, X., Purkey, M., Riedinger, N., Sanada, Y., Sauvage, J., Snyder, G., Susilawati, R., Takano, Y., Tasumi, E., Terada, T., Tomaru, H., Trembath-Reichert, E., Wang, D.T., and Yamada, Y. (2015) Exploring deep microbial life in coal-bearing sediment down to $\sim 2.5 \mathrm{~km}$ below the ocean floor. Science 349:420-424.

James Cleaves, H., Crapster-Pregont, E., Jonsson, C.M., Jonsson, C.L., Sverjensky, D.A., and Hazen, R.A. (2011) The adsorption of short single-stranded DNA oligomers to mineral surfaces. Chemosphere 83:1560-1567.

Johnson, J.C., Johnson, P.A., and Mardon, A.A. (2019) Soil sampling with nanoscale vibration sensors for on-site detection of microorganisms [abstract 5079]. In Mars Extant Life: What's Next? Conference Abstracts, Lunar and Planetary Institute, Houston. Available online at https://www.hou.usra.edu/ meetings/lifeonmars2019/pdf/5079.pdf

Johnson, S.S., Anslyn, E.V., Graham, H.V., Mahaffy, P.R., and Ellington, A.D. (2018) Fingerprinting non-terran biosignatures. Astrobiology 18:915-922.

Johnson, S.S., Graham, H.V., Des Marais, D.J., and Hazen, R.M. (2019a) Detecting life on Earth and the limits of analogy. In Planetary Astrobiology, edited by V. Meadows, G.N. Arney, B.E. Schmidt, and D.J. Des Marais, University of Arizona Press, Tucson, AZ, pp 121-150.

Johnson, S.S., Graham, H., Anslyn, E., Conrad, P., Cronin, L., Ellington, A., Elsila, J., Girguis, P., House, C., Kempes, C., Libby, E., Mahaffy, P., Nadeau, J., Sherwood Lollar, B., Steele, A., Chou, L., Grefenstette, N., and Da Poian, V. (2019b) Agnostic approaches to extant life detection [abstract 5026]. In Mars Extant Life: What's Next? Conference Abstracts, Lunar and Planetary Institute, Houston. Available online at https://www.hou.usra.edu/meetings/lifeonmars2019/ pdf/5026.pdf

Jones, D.S., Havlena, Z.E., and Macalady, J.L. (2019) Microbial ecology, evolution, and biosignature potential in isolated chemosynthetic cave ecosystems [abstract 5030]. In Mars Extant Life: What's Next? Conference Abstracts, Lunar and Planetary Institute, Houston. Available online at https:// www.hou.usra.edu/meetings/lifeonmars2019/pdf/5030.pdf

Jones, R.M., Goordial, J.M., and Orcutt, B.N. (2018) Low energy subsurface environments as extraterrestrial analogs. Front Microbiol 9, doi:10.3389/fmicb.2018.01605.

Joyce, J. (1994) Foreward. In Origins of Life: The Central Concepts, edited by D.W. Deamer and G.R. Fleischaker, Jones and Bartlett, Boston.

Junge, K., Eicken, H., and Deming, J.W. (2004) Bacterial activity at -2 to $-20^{\circ} \mathrm{C}$ in Arctic wintertime sea ice. Appl Environ Microbiol 70:550-557.

Kalita, H., Nallapu, R.T., Warren, A., and Thangavelautham, J. (2017) GNC of the SphereX Robot for extreme environment exploration on Mars. arXiv:1701.07550

King, G.M., DePoy, A., and Myers, M.R. (2019) Anaerobic carbon monoxide oxidation under very diverse conditions as a model for sub-surface Mars [abstract 5029]. In Mars Extant Life: What's Next? Conference Abstracts, Lunar and Planetary Institute, Houston. Available online at https://www.hou.usra.edu/meetings/ lifeonmars2019/pdf/5029.pdf

Kite, E.S. (2019) Geologic constraints on early Mars climate. Space Sci Rev 215, doi:10.1007/s11214-018-0575-5.

Klein, H.P. (1978) The Viking biological experiments on Mars. Icarus 34:666-674.
Klein, H.P. (1998) The search for life on Mars: what we learned from Viking. J Geophys Res Planets 103:28463-28466.

Klein, H.P., Horowitz, N.H., Levin, G.V., Oyama, V.I., Lederberg, J., Rich, A., Hubbard, J.S., Hobby, G.L., Straat, P.A., Berdahl, B.J., Carle, G.C., Brown, F.S., and Johnson, R.D. (1976) The Viking biological investigation: preliminary results. Science 194:99-105.

Koeppel, A.H.D., Trilling, D.E., Koch, G.W., Schwartz, E., and Edwards, C.S. (2019) Testing methods for detection of unfamiliar life in martian regolith [abstract 5100]. In Mars Extant Life: What's Next? Conference Abstracts, Lunar and Planetary Institute, Houston. Available online at https:// www.hou.usra.edu/meetings/lifeonmars2019/pdf/5100.pdf

Kring, D.A. (2019) Cyanobacteria soil crust and endoliths at Barringer meteorite Crater (aka Meteor Crater), Arizona [abstract 5081]. In Mars Extant Life: What's Next? Conference Abstracts, Lunar and Planetary Institute, Houston. Available online at https://www.hou.usra.edu/meetings/lifeonmars2019/ pdf/5081.pdf

Kring, D.A., Claeys, P., Gulick, S.P.S., Morgan, J.V., Collins, G.S., Bralower, T., Chenot, E., Christeson, G., Cockell, C., Coolen, M.J.L., Ferrière, L., Gebhardt, C., Goto, K., Jones, H., Lofi, J., Lowery, C., Mellett, C., Ocampo-Torres, R., Perez-Cruz, L., Pickersgill, A., Poelchau, M., Rae, A., Rasmussen, C., Rebolledo-Vieyra, M., Riller, U., Sato, H., Smit, J., Tikoo, S., Tomioka, N., Urrutia-Fucugauchi, J., Whalen, M., Wittmann, A., Xiao, L., Yamaguchi, K.E., and Zylberman, W. (2017) Chicxulub and the exploration of large peakring impact craters through scientific drilling. GSA Today 27: 4-8.

LaJoie, B., Alarcon, H., Mansor, M., and Xu, J. (2019) Interaction of sulface-reducers with hydrous sulfate minerals in water-restricted terrestrial gypsic settings: implication for the habitability of martian gypsic environments [abstract 5051]. In Mars Extant Life: What's Next? Conference Abstracts, Lunar and Planetary Institute, Houston. Available online at https://www.hou.usra.edu/meetings/lifeonmars2019/pdf/ 5051.pdf

Lanza, N.L., Fischer, W.W., Yeager, C., Lingappa, U., Ollila, A.M., Gasda, P.J., Lamm, S.N., Salvatore, M., Clegg, S.M., and Wiens, R.C. (2019) Targeting manganese minerals on Mars as potential biosignatures [abstract 5035]. In Mars Extant Life: What's Next? Conference Abstracts, Lunar and Planetary Institute, Houston. Available online at https:// www.hou.usra.edu/meetings/lifeonmars2019/pdf/5035.pdf

Laskar, J., Levrard, B., and Mustard, J.F. (2002) Orbital forcing of the martian polar layered deposits. Nature 419:375-377.

Lau, M.C.Y., Kieft, T.L., Kuloyo, O., Linage-Alvarez, B., Van Heerden, E., Lindsay, M.R., Magnabosco, C., Wang, W., Wiggins, J.B., Guo, L., Perlman, D.H., Kyin, S., Shwe, H.H., Harris, R.L., Oh, Y., Yi, M.J., Purtschert, R., Slater, G.F., Ono, S., Wei, S., Li, L., Lollar, B.S., and Onstott, T.C. (2016) An oligotrophic deep-subsurface community dependent on syntrophy is dominated by sulfur-driven autotrophic denitrifiers. Proc Natl Acad Sci USA 113:E7927-E7936.

Lee, P.A., Dyar, M.D., Sklute, E.C., Jarratt, A., and Mikucki, J.A. (2019) Got gas? Assessing non-methane volatile organic compounds as a biosignature for extant life [abstract 5095]. In Mars Extant Life: What's Next? Conference Abstracts, Lunar and Planetary Institute, Houston. Available online at https:// www.hou.usra.edu/meetings/lifeonmars2019/pdf/5095.pdf

Legatzki, A., Ortiz, M., Neilson, J.W., Dominguez, S., Andersen, G.L., Toomey, R.S., Pryor, B.M., Pierson, L.S., and Maier, R.M. (2011) Bacterial and archaeal community 
structure of two adjacent calcite speleothems in Kartchner Caverns, Arizona, USA. Geomicrobiol J 28:99-117.

Lester, E.D., Satomi, M., \& Ponce, A. (2007) Microflora of extreme arid Atacama Desert soils. Soil Biol Biochem 39: 704-708.

Léveillé, R.L., Ni, J., O’Connor, B., Whyte, L.G., and Patterson, C. (2019) Lava tube caves on Mars as refugia for microbial life [abstract 5042]. In Mars Extant Life: What's Next? Conference Abstracts, Lunar and Planetary Institute, Houston. Available online at https://www.hou.usra.edu/meetings/ lifeonmars2019/pdf/5042.pdf

Levin, G.V. (2019) Confirming extant life on Mars [abstract 5002]. In Mars Extant Life: What's Next? Conference Abstracts, Lunar and Planetary Institute, Houston. Available online at https://www.hou.usra.edu/meetings/lifeonmars2019/ pdf/5002.pdf

Levin, G.V. and Straat, P.A. (1981) A search for a nonbiological explanation of the Viking Labeled Release life detection experiment. Icarus 45:494-516.

Lewis, K.W., Peters, S., Gonter, K., Morrison, S., Schmerr, N., Vasavada, A.R., and Gabriel, T. (2019) A surface gravity traverse on Mars indicates low bedrock density at Gale Crater. Science 363:535-537.

Li, L., Wing, B.A., Bui, T.H., McDermott, J.M., Slater, G.F., Wei, S., Lacrampe-Couloume, G., and Lollar, B.S. (2016) Sulfur mass-independent fractionation in subsurface fracture waters indicates a long-standing sulfur cycle in Precambrian rocks. Nat Commun 7, doi:10.1038/ncomms13252.

Li, X., van Amerom, F., Kaplan, D., Grubisic, A., Danell, R., Getty, S., Castillo, M., Arevalo, R., Siljeström, S., Goetz, W., and Brinckerhoff, W. (2019) Mars analog sample study for ExoMars 2020 rover mission [abstract 5027]. In Mars Extant Life: What's Next? Conference Abstracts, Lunar and Planetary Institute, Houston. Available online at https://www.hou.usra.edu/ meetings/lifeonmars2019/pdf/5027.pdf

Lin, L.H., Wang, P.L., Rumble, D., Lippmann-Pipke, J., Boice, E., Pratt, L.M., Lollar, B.S., Brodie, E.L., Hazen, T.C., Andersen, G.L., DeSantis, T.Z., Moser, D.P., Kershaw, D., and Onstott, T.C. (2006) Long-term sustainability of a highenergy, low-diweniff crystal-biome. Science 314:479-482.

Lippmann-Pipke, J., Sherwood Lollar, B., Niedermann, S., Stroncik, N.A., Naumann, R., van Heerden, E., and Onstott, T.C. (2011) Neon identifies two billion year old fluid component in Kaapvaal Craton. Chem Geol 283:287-296.

Lloyd, K.G., Steen, A.D., Ladau, J., Yin, J., and Crosby, L. (2018) Phylogenetically novel uncultured microbial cells dominate earth microbiomes. MSystems 3, doi:10.1128/msystems.0005518.

Lollar, G.S., Warr, O., Telling, J., Osburn, M.R., and Lollar, B.S. (2019) 'Follow the Water': hydrogeochemical constraints on microbial investigations $2.4 \mathrm{~km}$ below surface at the Kidd Creek Deep Fluid and Deep Life Observatory. Geomicrobiol J 36:859-872.

Lynch, K.L., Andrew Jackson, W., Rey, K., Spear, J.R., Rosenzweig, F., and Munakata-Marr, J. (2019a) Evidence for biotic perchlorate reduction in naturally perchlorate-rich sediments of Pilot Valley Basin, Utah. Astrobiology 19:629-641.

Lynch, K.L., Rey, K.A., Bond, R.J., Jackson, W.A., Rosenzweig, R.F., Biddle, J.F., and Christman, G. (2019b) The Pilot Valley Basin, Utah: a model system for extant life in the martian subsurface [abstract 5056]. In Mars Extant Life: What's Next? Conference Abstracts, Lunar and Planetary Institute, Houston. Available online at https://www.hou.usra.edu/meetings/ lifeonmars2019/pdf/5056.pdf
Mackelprang, R., Beaty, D.W., Carrier, B.L., and the iMOST Team. (2019) Strategies and recommendations for the search for extant life [abstract 5015]. In Mars Extant Life: What's Next? Conference Abstracts, Lunar and Planetary Institute, Houston. Available online at https://www.hou.usra.edu/ meetings/lifeonmars2019/pdf/5015.pdf

Magnabosco, C., Lin, L.H., Dong, H., Bomberg, M., Ghiorse, W., Stan-Lotter, H., Pedersen, K., Kieft, T.L., van Heerden, E., and Onstott, T.C. (2018) The biomass and biodiversity of the continental subsurface. Nat Geosci 11:707-717.

Mahaffy, P.R., Webster, C.R., Cabane, M., Conrad, P.G., Coll, P., Atreya, S.K., Arvey, R., Barciniak, M., Benna, M., Bleacher, L., Brinckerhoff, W.B., Eigenbrode, J.L., Carignan, D., Cascia, M., Chalmers, R.A., Dworkin, J.P., Errigo, T., Everson, P., Franz, H., Farley, R., Feng, S., Frazier, G., Freissinet, C., Glavin, D.P., Harpold, D.N., Hawk, D., Holmes, V., Johnson, C.S., Jones, A., Jordan, P., Kellogg, J., Lewis, J., Lyness, E., Malespin, C.A., Martin, D.K., Maurer, J., McAdam, A.C., McLennan, D., Nolan, T.J., Noriega, M., Pavlov, A.A., Prats, B., Raaen, E., Sheinman, O., Sheppard, D., Smith, J., Stern, J.C., Tan, F., Trainer, M., Ming, D.W., Morris, R.V., Jones, J., Gundersen, C., Steele, A., Wray, J., Botta, O., Leshin, L.A., Owen, T., Battel, S., Jakosky, B.M., Manning, H., Squyres, S., Navarro-González, R., McKay, C.P., Raulin, F., Sternberg, R., Buch, A., Sorensen, P., Kline-Schoder, R., Coscia, D., Szopa, C., Teinturier, S., Baffes, C., Feldman, J., Flesch, G., Forouhar, S., Garcia, R., Keymeulen, D., Woodward, S., Block, B.P., Arnett, K., Miller, R., Edmonson, C., Gorevan, S., and Mumm, E. (2012) The Sample Analysis at Mars Investigation and Instrument suite. Space Sci Rev 170:401-478.

Mahaffy, P.R., Arevalo, R.D., Brinckerhoff, W.B., Cook, J.E., Danell, R.M., Getty, S.A., Graham, H.V., Johnson, S.S., Trainer, M.G., and Li, X. (2019) Advanced mass spectrometer techniques for agnostic surveys for martian biosignatures [abstract 5022]. In Mars Extant Life: What's Next? Conference Abstracts, Lunar and Planetary Institute, Houston. Available online at https:// www.hou.usra.edu/meetings/lifeonmars2019/pdf/5022.pdf

Mancinelli, R.L., Fahlen, T.F., Landheim, R., and Klovstad, M.R. (2004) Brines and evaporites: analogs for martian life. Adv Space Res 33:1244-1246.

Mansor, M., Harouaka, K., Gonzales, M.S., Macalady, J.L., and Fantle, M.S. (2019) Transport-coupled sulfur isotopic fractionation by sulfur oxidizing microbes as biosignatures on the walls of Earth and martian caves [abstract 5018]. In Mars Extant Life: What's Next? Conference Abstracts, Lunar and Planetary Institute, Houston. Available online at https:// www.hou.usra.edu/meetings/lifeonmars2019/pdf/5018.pdf

Mardon, A.A., Zhou, G., and Mardon, C. (2019) Biologyrelated parameters and potential life identifiers on Mars [abstract 5071]. In Mars Extant Life: What's Next? Conference Abstracts, Lunar and Planetary Institute, Houston. Available online at https://www.hou.usra.edu/meetings/lifeonmars2019/ pdf/5071.pdf

Marshall, S.M., Murray, A.R.G., and Cronin, L. (2017) A probabilistic framework for identifying biosignatures using Pathway Complexity. Philos Trans A Math Phys Eng Sci 375, doi:10.1098/rsta.2016.0342.

Martin, D. and Cockell, C.S. (2015) PELS (Planetary Environmental Liquid Simulator): a new type of simulation facility to study extraterrestrial aqueous environments. Astrobiology 15: 111-118.

McKay, C.P. and Stoker, C.R. (1989) The early environment and its evolution on Mars: implication for life. Rev Geophys 27, doi:10.1029/RG027i002p00189. 
Melim, L.A., Northup, D.E., Boston, P.J., and Spilde, M.N. (2016) Preservation of fossil microbes and biofilm in cave pool carbonates and comparison to other microbial carbonate environments. Palaios 31:177-189.

Mellon, M.T., Arvidson, R.E., Sizemore, H.G., Searls, M.L., Blaney, D.L., Cull, S., Hecht, M.H., Heet, T.L., Keller, H.U., Lemmon, M.T., Markiewicz, W.J., Ming, D.W., Morris, R.V., Pike, W.T., and Zent, A.P. (2009) Ground ice at the Phoenix landing site: stability state and origin. J Geophys Res 114, doi:10.1029/2009JE003417.

MEPAG. (2018) Mars Science Goals, Objectives, Investigations, and Priorities: 2018, Mars Exploration Program Analysis Group (MEPAG). Retrieved from https://mepag.jpl.nasa.gov/ reports/MEPAG\%20Goals_Document_2018.pdf

Michalski, J.R., Cuadros, J., Niles, P.B., Parnell, J., Deanne Rogers, A., and Wright, S.P. (2013) Groundwater activity on Mars and implications for a deep biosphere. Nat Geosci 6: 133-138.

Navarro-González, R., Vargas, E., de la Rosa, J., Raga, A.C., and McKay, C.P. (2010) Reanalysis of the Viking results suggests perchlorate and organics at midlatitudes on Mars. $J$ Geophys Res 115, doi:10.1029/2010JE003599.

Nellessen, M.A., Crossey, L., Gasda, P.J., Peterson, E., Lanza, N.L., Yeager, C., Labouriau, A., Wiens, R.C., Clegg, S., Reyes-Newell, A., Delapp, D., and Das, D. (2019) Boron adsorption in martian clay analogs: significance for martian prebiotic processes and groundwater geochemistry [abstract 5102]. In Mars Extant Life: What's Next? Conference Abstracts, Lunar and Planetary Institute, Houston. Available online at https://www.hou.usra.edu/meetings/lifeonmars2019/pdf/ 5102.pdf

Neveu, M., Hays, L.E., Voytek, M.A., New, M.H., and Schulte, M.D. (2018) The ladder of life detection. Astrobiology 18: 1375-1402.

Newsom, H.E., Crossey, L.J., Hoffman, M.E., Ganter, G.E., and Baker, A.M. (2019) The role of large impact craters in the search for extant life on Mars [abstract 5049]. In Mars Extant Life: What's Next? Conference Abstracts, Lunar and Planetary Institute, Houston. Available online at https://www.hou.usra.edu/ meetings/lifeonmars2019/pdf/5049.pdf

Nicholson, W.L., Munakata, N., Horneck, G., Melosh, H.J., and Setlow, P. (2000) Resistance of Bacillus endospores to extreme terrestrial and extraterrestrial environments. Microbiol Mol Biol Rev 64:548-572.

Northup, D.E., Melim, L.A., Spilde, M.N., Hathaway, J.J.M., Garcia, M.G., Moya, M., Stone, F.D., Boston, P.J., Dapkevicius, M.L.N.E., and Riquelme, C. (2011) Lava cave microbial communities within mats and secondary mineral deposits: implications for life detection on other planets. Astrobiology 11:601-618.

Northup, D.E., Hathaway, J.J.M., Spilde, M.N., Moser, D.P., and Blank, J.G. (2019) Investigating the mineral:microbe continuum in lava caves to enhance selection of life detection targets [abstract 5037]. In Mars Extant Life: What's Next? Conference Abstracts, Lunar and Planetary Institute, Houston. Available online at https://www.hou.usra.edu/meetings/ lifeonmars2019/pdf/5037.pdf

Novak, C.M., Stockton, A.M., Sutton, S.M., Cable, M.L., Duca, Z.A., Tan, G.K., Cullen, D., Balayan, V., and Geppert W. (2019) Suite of geochemical and spatial analogues for planetary life detection [abstract 5005]. In Mars Extant Life: What's Next? Conference Abstracts, Lunar and Planetary Institute, Houston. Available online at https://www.hou.usra.edu/ meetings/lifeonmars2019/pdf/5005.pdf
O'Connor, B.R.W., Léveillé, R.J., and Whyte, L.G. (2019) Microbial community characterization of lava tube ice on Earth to determine its habitability on Mars [abstract 5105]. In Mars Extant Life: What's Next? Conference Abstracts, Lunar and Planetary Institute, Houston. Available online at https:// www.hou.usra.edu/meetings/lifeonmars2019/pdf/5105.pdf

Olsson-Francis, K. and Cockell, C.S. (2010) Experimental methods for studying microbial survival in extraterrestrial environments. J Microbiol Methods 80, doi:10.1016/j.mimet.2009.10.004.

Onstott, T.C., Ehlmann, B.L., Sapers, H., Coleman, M., Ivarsson, M., Marlow, J.J., Neubeck, A., and Niles, P. (2019a) Paleo-rock-hosted life on Earth and the search on Mars: a review and strategy for exploration. Astrobiology 19:12301262.

Onstott, T.C., Rusley, C., Liang, R., Garvin, Z., Nissin, D., Harris, R., Higgins, J., Slater, N., Van Heerden, E., Freese, B., Leibenberg, B., Ogasawara, H., van Heerden, E., Cason, E., Vermeulen, J., Sherwood Lollar, B., Kieft, T., Wiersberg, T., Zimmer, M., Walters, C., Freifeld, B., and Michalski, J.R. (2019b) Briny SLiMEs in the subsurface of Earth and Mars [abstract 5025]. In Mars Extant Life: What's Next? Conference Abstracts, Lunar and Planetary Institute, Houston. Available online at https://www.hou.usra.edu/meetings/ lifeonmars2019/pdf/5025.pdf

Orgel, L.E. (2004) Prebiotic chemistry and the origin of the RNA world. Crit Rev Biochem Mol Biol 39:99-123.

Orosei, R., Lauro, S.E., Pettinelli, E., Cicchetti, A., Coradini, M., Cosciotti, B., Di Paolo, F., Flamini, E., Mattei, E., Pajola, M., Soldovieri, F., Cartacci, M., Cassenti, F., Frigeri, A., Giuppi, S., Martufi, R., Masdea, A., Mitri, G., Nenna, C., Noschese, R., Restano, M., and Seu, R. (2018) Radar evidence of subglacial liquid water on Mars. Science 361:490-493.

Osterloo, M.M., Anderson, F.S., Hamilton, V.E., and Hynek, B.M. (2010) Geologic context of proposed chloride-bearing materials on Mars. J Geophys Res Planets 115, doi:10.1029/ 2010JE003613.

Oyama, V.I. and Berdahl, B.J. (1979) A model of martian surface chemistry. J Mol Evol 14:199-210.

Oyama, V.I., Berdahl, B.J., and Carle, G.C. (1977) Preliminary findings of the Viking gas exchange experiment and a model for martian surface chemistry. Nature 265:110-114.

Palmer, A.N. (1991) Origin and morphology of limestone caves. Geol Soc Am Bull 103:1-21.

Parkes, R.J., Cragg, B., Roussel, E., Webster, G., Weightman, A., and Sass, H. (2014) A review of prokaryotic populations and processes in sub-seafloor sediments, including biosphere: geosphere interactions. Mar Geol 352:409-425.

Parness, A., Abcouwer, N., Fuller, C., Wiltsie, N., Nash, J., and Kennedy, B. (2017) LEMUR 3: a limbed climbing robot for extreme terrain mobility in space. In 2017 IEEE International Conference on Robotics and Automation (ICRA), IEEE, Piscataway, NJ, doi:10.1109/ICRA.2017.7989643.

Parro, V., De Diego-Castilla, G., Rodríguez-Manfredi, J.A., Rivas, L.A., Blanco-López, Y., Sebastián, E., Romeral, J., Compostizo, C., Herrero, P.L., García-Marín, A., MorenoPaz, M., García-Villadangos, M., Cruz-Gil, P., Peinado, V., Martín-Soler, J., Pérez-Mercader, J., and Gómez-Elvira, J. (2011) SOLID3: A multiplex antibody microarray-based optical sensor instrument for in situ life detection in planetary exploration. Astrobiology 11:15-28.

Pavlov, A.A., Davis, J., Johnson, J., and Pavlov, A.K. (2019) Gas pockets in the shallow martian subsurface-a new environmental niche for hypothesized Mars extant life [abstract 
5057]. In Mars Extant Life: What's Next? Conference Abstracts, Lunar and Planetary Institute, Houston. Available online at https://www.hou.usra.edu/meetings/lifeonmars2019/ pdf/5057.pdf

Perl, S.M. and Baxter, B.K. (2020) Great Salt Lake as an astrobiology analogue for ancient martian hypersaline aqueous systems. In Great Salt Lake: Biology of a Terminal Lake in the Age of Change, edited by B.K. Baxter and J. Butler, Springer, New York.

Perl, S.M., Baxter, B.K., and Celestian, A.J. (2019) Hypersaline and sedimentological advantages on the preservation of extant biological activity in modern martian analogue settings [abstract 5031]. In Mars Extant Life: What's Next? Conference Abstracts, Lunar and Planetary Institute, Houston. Available online at https:/www.hou.usra.edu/meetings/ lifeonmars2019/pdf/5031.pdf

Plesa, A.-C., Grott, M., Tosi, N., Breuer, D., Spohn, T., and Wieczorek, M.A. (2016) How large are present-day heat flux variations across the surface of Mars? J Geophys Res Planets 121:2386-2403.

Plumb, R.C., Tantayanon, R., Libby, M., and Xu, W.W. (1989) Chemical model for Viking biology experiments: Implications for the composition of the martian regolith. Nature 338: 633-635.

Ponnamperuma, C., Shimoyama, A., Yamada, M., Hobo, T., and Ramsay, P.A.L. (1977) Possible surface reactions on Mars: implications for Viking biology results. Science 197: 455-457.

Purkamo, L., Kietäväinen, R., Nuppunen-Puputti, M., Bomberg, M., and Cousins, C. (2020) Ultradeep microbial communities at $4.4 \mathrm{~km}$ within crystalline bedrock: implications for habitability in a planetary context. Life 10, doi:10.3390/life10010002.

Quinn, R.C. and Zent, A.P. (1999) Peroxide-modified titanium dioxide: a chemical analog of putative martian soil oxidants. Orig Life Evol Biosph 29:59-72.

Quinn, R.C., Martucci, H.F.H., Miller, S.R., Bryson, C.E., Grunthaner, F.J., and Grunthaner, P.J. (2013) Perchlorate radiolysis on Mars and the origin of martian soil reactivity. Astrobiology 13:515-520.

Quinn, R.C., Ricco, A.J., Boone, T.D., Bramall, N., Bywaters, K., Chin, M.M., Chinn, T.N., Forgione, J.B., Harrison, D.J., Hoac, T., Kelly, E.T., Koehne, J., Kintz, G., Lee, A.K.-S., McCutcheon, G.C., Parenteau, M.N., Radosevich, L.A., Shimada, J.A., Tan, M.X., Timucin, L.R., and Wang, J.L. (2019) Microfluidic approaches to searching for extant life on Mars [abstract 5032]. In Mars Extant Life: What's Next? Conference Abstracts, Lunar and Planetary Institute, Houston. Available online at https://www.hou.usra.edu/meetings/lifeonmars2019/ pdf/5032.pdf

Rabbow, E., Parpart, A., and Reitz, G. (2016) The Planetary and Space Simulation Facilities at DLR Cologne. Microgravity Sci Technol 28:215-229.

Ricardo, A., Carrigan, M.A., Olcott, A.N., and Benner, S.A. (2004) Borate minerals stabilize ribose. Science 303, doi: 10.1126/science.1092464.

Richards, M.A., Duncan, R.A., and Courtillot, V.E. (1989) Flood basalts and hot-spot tracks: plume heads and tails. Science 246, doi:10.1126/science.246.4926.103.

Richardson, M.I. and Mischna, M.A. (2005) Long-term evolution of transient liquid water on Mars. J Geophys Res Planets 110, doi:10.1029/2004JE002367.

Rothschild, L.J. and Mancinelli, R.L. (2001) Life in extreme environments. Nature 409:1092-1101.
Rowe, L.A., Davidson, K., Smith, C., Kovarik, C., and Peller, J. (2019) Comparing the stability of non-proteinogenic amino acids to proteinogenic amino acids when irradiated and in perchlorate spike Mars regolith [abstract 5010]. In Mars Extant Life: What's Next? Conference Abstracts, Lunar and Planetary Institute, Houston. Available online at https:// www.hou.usra.edu/meetings/lifeonmars2019/pdf/5010.pdf

Rummel, J.D., Beaty, D.W., Jones, M.A., Bakermans, C., Barlow, N.G., Boston, P.J., Chevrier, V.F., Clark, B.C., de Vera, J.-P.P., Gough, R.V., Hallsworth, J.E., Head, J.W., Hipkin, V.J., Kieft, T.L., McEwen, A.S., Mellon, M.T., Mikucki, J.A., Nicholson, W.L., Omelon, C.R., Peterson, R., Roden, E.E., Sherwood Lollar, B., Tanaka, K.L., Viola, D., and Wray, J.J. (2014) A new analysis of Mars "Special Regions": findings of the Second MEPAG Special Regions Science Analysis Group (SR-SAG2). Astrobiology 14:887-968.

Schoepp-Cothenet, B., Van Lis, R., Atteia, A., Baymann, F., Capowiez, L., Ducluzeau, A.L., Duval, S., Ten Brink, F., Russell, M.J., and Nitschke, W. (2013) On the universal core of bioenergetics. Biochim Biophys Acta Bioenerg 1827:7993.

Schopf, J.W., Kudryavtsev, A.B., Czaja, A.D., and Tripathi, A.B. (2007) Evidence of Archean life: stromatolites and microfossils. Precambrian Res 158:141-155.

Schrenk, M.O., Brazelton, W.J., and Lang, S.Q. (2013) Serpentinization, carbon, and deep life. Rev Mineral Geochem 75:575-606.

Schuerger, A.C. and Britt, D. (2019) Fast degassing rates under simulated martian conditions indicate that rock void space are unlikely to maintain habitable conditions on Mars [abstract 5004]. In Mars Extant Life: What's Next? Conference Abstracts, Lunar and Planetary Institute, Houston. Available online at https://www.hou.usra.edu/meetings/lifeonmars2019/ pdf/5004.pdf

Schuerger, A.C. and Clark, B.C. (2008) Viking biology experiments: lessons learned and the role of ecology in future Mars life-detection experiments. Space Sci Rev 135:233243.

Schuerger, A.C. and Nicholson, W.L. (2016) Twenty species of hypobarophilic bacteria recovered from diverse soils exhibit growth under simulated martian conditions at $0.7 \mathrm{kPa}$. Astrobiology 16:964-976.

Schuerger, A.C., Fajardo-Cavazos, P., Clausen, C.A., Moores, J.E., Smith, P.H., and Nicholson, W.L. (2008) Slow degradation of ATP in simulated martian environments suggests long residence times for the biosignature molecule on spacecraft surfaces on Mars. Icarus 194:86-100.

Schuerger, A.C., Ulrich, R., Berry, B.J., and Nicholson, W.L. (2013) Growth of Serratia liquefaciens under $7 \mathrm{mbar}, 0^{\circ} \mathrm{C}$, and $\mathrm{CO}_{2}$-enriched anoxic atmospheres. Astrobiology 13:115131.

Schulze-Makuch, D. (2019) The case for a robotic in-situ life detection mission to explore potential habitats on Mars [abstract 5009]. In Mars Extant Life: What's Next? Conference Abstracts, Lunar and Planetary Institute, Houston. Available online at https://www.hou.usra.edu/meetings/lifeonmars2019/ pdf/5009.pdf

Schulze-Makuch, D. and Irwin, L.N. (2018) Life in the Universe: Expectations and Constraints, Springer International Publishing, New York.

Schulze-Makuch, D., Fairén, A.G., and Davila, A. (2013) Locally targeted ecosynthesis: a proactive in situ search for extant life on other worlds. Astrobiology 13:674-678. 
Schwendner, P. and Schuerger, A.C. (2019) Spacecraft microorganisms and their impact on planetary protection-can they grow at simulated martian atmospheric pressure? [abstract 5006]. In Mars Extant Life: What's Next? Conference Abstracts, Lunar and Planetary Institute, Houston. Available online at https://www.hou.usra.edu/meetings/lifeonmars2019/ pdf/5006.pdf

Schwendner, P. and Schuerger, A.C. (2020) Exploring microbial activity in low-pressure environments. In Astrobiology: Current, Evolving, and Emerging Perspectives, Caister Academic Press, Norfolk, UK, doi:10.21775/9781912530304.07.

Scuderi, L.A., Gallegos, Z.E., Newsom, H.E., and Wiens, R.C. (2019) Amazonian groundwater springline at Peace Vallis Fan, Gale Crater; implications for a late period of surface habitability [abstract 5043]. In Mars Extant Life: What's Next? Conference Abstracts, Lunar and Planetary Institute, Houston. Available online at https://www.hou.usra.edu/ meetings/lifeonmars2019/pdf/5043.pdf

Sears, D.W.G., Benoit, P.H., McKeever, S.W.S., Banerjee, D., Kral, T., Stites, W., Roe, L., Jansma, P., and Mattioli, G (2002) Investigation of biological, chemical and physical processes on and in planetary surfaces by laboratory simulation. Planet Space Sci 50:821-828.

Sherwood Lollar, B., Frape, S.K., Weise, S.M., Fritz, P., Macko, S.A., and Welhan, J.A. (1993) Abiogenic methanogenesis in crystalline rocks. Geochim Cosmochim Acta 57: 5087-5097.

Sherwood Lollar, B., Lacrampe-Couloume, G., Voglesonger, K., Onstott, T.C., Pratt, L.M., and Slater, G. F. (2008) Isotopic signatures of $\mathrm{CH}_{4}$ and higher hydrocarbon gases from Precambrian Shield sites: a model for abiogenic polymerization of hydrocarbons. Geochim Cosmochim Acta 72:47784795 .

Sitti, M. and Fearing, R.S. (2003) Synthetic gecko foot-hair micro/nano-structures for future wall-climbing robots. In 2003 IEEE International Conference on Robotics and Automation, IEEE, Piscataway, NJ, doi:10.1109/robot.2003.1241750.

Sizemore, H.G, Demchenko, V., Zent, A.P., Rempel, A.W., and Stillman, D.E. (2019) Habitability of high latitude martian ground ice, revisited [abstract 5101]. In Mars Extant Life: What's Next? Conference Abstracts, Lunar and Planetary Institute, Houston. Available online at https://www.hou.usra.edu/ meetings/lifeonmars2019/pdf/5101.pdf

Spilde, M.N., Medley, J.J., Northup, D.E., and Boston, P.J. (2019) Biomarkers in lava caves: an analog for the search for life on Mars [abstract 5036]. In Mars Extant Life: What's Next? Conference Abstracts, Lunar and Planetary Institute, Houston. Available online at https://www.hou.usra.edu/meetings/ lifeonmars2019/pdf/5036.pdf

Stamenković, V., Ward, L.M., Mischna, M., and Fischer, W.W. (2018) $\mathrm{O}_{2}$ solubility in martian near-surface environments and implications for aerobic life. Nat Geosci 11:905-909.

Stamenković, V., Plesa, A.C., Breuer, D., Burgin, M., Grimm, R., Arumugam, D., Beauchamp, R., Barba, N., Manthena, R., Wright, D., Wilcox, B., Carpenter, K., and Edwards, C. (2019a) Mars subsurface hydrology in 4D and implications for extant life [abstract 5052]. In Mars Extant Life: What's Next? Conference Abstracts, Lunar and Planetary Institute, Houston. Available online at https://www.hou.usra.edu/meetings/lifeonmars2019/ pdf/5052.pdf

Stamenković, V., Ward, L.M., Mischna, M., and Fischer, W.W. (2019b) $\mathrm{O}_{2}$ solubility in martian surface environments and implications for extant aerobic life on Mars [abstract 5045]. In Mars Extant Life: What's Next? Conference Abstracts,
Lunar and Planetary Institute, Houston. Available online at https://www.hou.usra.edu/meetings/lifeonmars2019/pdf/5045.pdf Stamenković, V., Beegle, L.W., Zacny, K., Arumugam, D.D., Baglioni, P., Barba, N., Baross, J., Bell, M.S., Bhartia, R., Blank, J.G., Boston, P.J., Breuer, D., Brinckerhoff, W., Burgin, M.S., Cooper, I., Cormarkovic, V., Davila, A., Davis, R.M., Edwards, C., Etiope, G., Fischer, W.W., Glavin, D.P., Grimm, R.E., Inagaki, F., Kirschvink, J.L., Kobayashi, A., Komarek, T., Malaska, M., Michalski, J., Ménez, B., Mischna, M., Moser, D., Mustard, J., Onstott, T.C., Orphan, V.J., Osburn, M.R., Plaut, J., Plesa, A.C., Putzig, N., Rogers, K.L., Rothschild, L., Russell, M., Sapers, H., Lollar, B.S., Spohn, T., Tarnas, J.D., Tuite, M., Viola, D., Ward, L.M., Wilcox, B., and Woolley, R. (2019c) The next frontier for planetary and human exploration. Nat Astron 3:116-120.

Stephenson, J.D., Hallis, L.J., Nagashima, K., and Freeland, S.J. (2013) Boron enrichment in martian clay. PLOS ONE 8, doi: 10.1371/journal.pone.0064624.

Stevens, T.O. and McKinley, J.P. (2000) Abiotic controls on $\mathrm{H}_{2}$ production from basalt-water reactions and implications for aquifer biogeochemistry. Environ Sci Technol 34:826831.

Stoker, C.R. (2019) Search for life in high latitude ground ice on Mars [abstract 5107]. In Mars Extant Life: What's Next? Conference Abstracts, Lunar and Planetary Institute, Houston. Available online at https://www.hou.usra.edu/meetings/ lifeonmars2019/pdf/5107.pdf

Stoker, C.R., Zent, A., Catling, D.C., Douglas, S., Marshall, J.R., Archer, D., Clark, B., Kounaves, S.P., Lemmon, M.T., Quinn, R., Renno, N., Smith, P.H., and Young, S.M.M. (2010) Habitability of the Phoenix landing site. J Geophys Res 115, doi:10.1029/2009JE003421.

Stoltenburg, R., Reinemann, C., and Strehlitz, B. (2007) SELEX-A (r)evolutionary method to generate high-affinity nucleic acid ligands. Biomol Eng 24:381-403.

Stromberg, J.M., Parkinson, A., Morison, M., Cloutis, E., Casson, N., Applin, D., Poitras, J., Marti, A.M., Maggiori, C., Cousins, C., Whyte, L., Kruzelecky, R., Das, D., Leveille, R., Berlo, K., Sharma, S.K., Acosta-Maeda, T., Daly, M., and Lalla, E. (2019) Biosignature detection by Mars rover equivalent instruments in samples from the CanMars Mars Sample Return analogue deployment. Planet Space Sci 176, doi:10.1016/j.pss.2019.06.007.

Sun, H. and $\mathrm{Zu}$, Y. (2015) A highlight of recent advances in aptamer technology and its application. Molecules 20:1195911980.

Szostak, J.W., Bartel, D.P., and Luisi, P.L. (2001) Synthesizing life. Nature 409:387-390.

Tarasashvili, M.V. and Aleksidze, N.D. (2019) Possible biological origin of the carbonates in the martian regolith [abstract 5014]. In Mars Extant Life: What's Next? Conference Abstracts, Lunar and Planetary Institute, Houston. Available online at https://www.hou.usra.edu/meetings/lifeonmars2019/ pdf/5014.pdf

Tarnas, J.D., Mustard, J.F., Sherwood Lollar, B., Bramble, M.S., Cannon, K.M., Palumbo, A.M., and Plesa, A.C. (2018) Radiolytic $\mathrm{H}_{2}$ production on Noachian Mars: implications for habitability and atmospheric warming. Earth Planet Sci Lett 502:133-145.

Tarnas, J.D., Mustard, J.F., Sherwood Lollar, B., Warr, O., Palumbo, A.M., and Plesa, A.-C.. (2019) Deep groundwaters on Earth as analogs for modern martian habitats [abstract 5104]. In Mars Extant Life: What's Next? Conference Abstracts, Lunar and Planetary Institute, Houston. Available 
online at https://www.hou.usra.edu/meetings/lifeonmars2019/ pdf/5104.pdf

ten Kate, I.L., Ruiterkamp, R., Botta, O., Lehmann, B., Hernandez, C.G., Boudin, N., Foing, B.H., and Ehrenfreund, P. (2002) Investigating complex organic compounds in a simulated Mars environment. Int J Astrobiol 1:387-399.

Thangavelautham, J., Robinson, M.S., Taits, A., McKinney, T., Amidan, S., and Polak, A. (2014) Flying, hopping pit-bots for cave and lava tube exploration on the Moon and Mars. arXiv: 1701.07799

Thomas, N.H., Ehlmann, B.L., Meslin, P.-Y., Rapin, W., Anderson, D.E., Rivera-Hernández, F., Forni, O., Schröder, S., Cousin, A., Mangold, N., Gellert, R., Gasnault, O., and Wiens, R.C. (2019) Mars Science Laboratory observations of chloride salts in Gale Crater, Mars. Geophys Res Lett 46: 10754-10763.

Thomas, R.J., Potter-McIntyre, S.L., and Hynek, B.M. (2017) Large-scale fluid-deposited mineralization in Margaritifer Terra, Mars. Geophys Res Lett 44:6579-6588.

Toner, J.D. and Catling, D.C. (2016) Water activities of Na$\mathrm{ClO}_{4}, \mathrm{Ca}\left(\mathrm{ClO}_{4}\right)_{2}$, and $\mathrm{Mg}\left(\mathrm{ClO}_{4}\right)_{2}$ brines from experimental heat capacities: water activity $>0.6$ below 200 K. Geochim Cosmochim Acta 181:164-174.

Toner, J.D., Catling, D.C., and Light, B. (2014) The formation of supercooled brines, viscous liquids, and low-temperature perchlorate glasses in aqueous solutions relevant to Mars. Icarus 233:36-47.

Toomey, R.S., III. (2009) Geological monitoring of caves and associated landscapes. In Geological Monitoring, edited by R. Young and L. Norby, Geological Society of America, Boulder, CO, p. 27-46.

Uckert, K., Chanover, N.J., Getty, S., Voelz, D.G., Brinckerhoff, W.B., Mcmillan, N., Xiao, X., Boston, P.J., Li, X., Mcadam, A., Glenar, D.A., and Chavez, A. (2017) The characterization of biosignatures in caves using an instrument suite. Astrobiology 17:1203-1218.

Viola, D. and McKay, C.P. (2019) Equatorial alpine regions as a scientific analog for past/present life on Mars [abstract 5099]. In Mars Extant Life: What's Next? Conference Abstracts, Lunar and Planetary Institute, Houston. Available online at https://www.hou.usra.edu/meetings/lifeonmars2019/ pdf/5099.pdf

Wade, B.D. and Lenski, R.E. (2019) Experimentally evolved tolerance to desiccation and UV-C radiation in E. coli and its implications for extant life in martian near-surface environments [abstract 5053]. In Mars Extant Life: What's Next? Conference Abstracts, Lunar and Planetary Institute, Houston. Available online at https://www.hou.usra.edu/meetings/ lifeonmars2019/pdf/5053.pdf

Walker, C.J., Weatherspoon, C.I., and Markushin, Y. (2019) Efficacy of machine learning techniques in analyzing amino acids and minerals using Fourier transform infrared spectroscopy [abstract 5103]. In Mars Extant Life: What's Next? Conference Abstracts, Lunar and Planetary Institute, Houston. Available online at https://www.hou.usra.edu/meetings/ lifeonmars2019/pdf/5103.pdf

Walter, M.R. (1994) Stromatolites: the main geological source of information on the evolution of the early benthos. In Early Life on Earth. Nobel Symposium No 84, edited by S. Bentson, Columbia University Press, New York, pp 270-286.

Ward, J.A., Slater, G.F., Moser, D.P., Lin, L.H., LacrampeCouloume, G., Bonin, A.S., Davidson, M., Hall, J.A., Mislowack, B., Bellamy, R.E.S., Onstott, T.C., and Sherwood Lollar, B. (2004) Microbial hydrocarbon gases in the Wit- watersrand Basin, South Africa: implications for the deep biosphere. Geochim Cosmochim Acta 68:3239-3250.

Warr, O., Sherwood Lollar, B., Fellowes, J., Sutcliffe, C.N., McDermott, J.M., Holland, G., Mabry, J.C., and Ballentine, C.J. (2018) Tracing ancient hydrogeological fracture network age and compartmentalisation using noble gases. Geochim Cosmochim Acta 222:340-362.

Webster, C.R., Mahaffy, P.R., Atreya, S.K., Moores, J.E., Flesch, G.J., Malespin, C., McKay, C.P., Martinez, G., Smith, C.L., Martin-Torres, J., Gomez-Elvira, J., Zorzano, M.P., Wong, M.H., Trainer, M.G., Steele, A., Archer, D., Sutter, B., Coll, P.J., Freissinet, C., Meslin, P.Y., Gough, R.V., House, C.H., Pavlov, A., Eigenbrode, J.L., Glavin, D.P., Pearson, J.C., Keymeulen, D., Christensen, L.E., Schwenzer, S.P., Navarro-Gonzalez, R., Pla-García, J., Rafkin, S.C.R., Vicente-Retortillo, Á., Kahanpää, H., Viudez-Moreiras, D., Smith, M.D., Harri, A.M., Genzer, M., Hassler, D.M., Lemmon, M., Crisp, J., Sander, S.P., Zurek, R.W., and Vasavada, A.R. (2018) Background levels of methane in Mars' atmosphere show strong seasonal variations. Science 360:10931096.

Webster, K.D. (2019) Developing cave air as a biosignature [abstract 5048]. In Mars Extant Life: What's Next? Conference Abstracts, Lunar and Planetary Institute, Houston. Available online at https://www.hou.usra.edu/meetings/ lifeonmars2019/pdf/5048.pdf

Webster, K.D., Drobniak, A., Etiope, G., Mastalerz, M., Sauer, P.E., and Schimmelmann, A. (2018) Subterranean karst environments as a global sink for atmospheric methane. Earth Planet Sci Lett 485:9-18.

Wei, S. (2017) Isotopic insights into the origin of dissolved sulfate and the sulfate-supported microbial processes in deep subsurface fracture waters in the Witwatersrand Basin, South Africa. Master of Science thesis, University of Alberta, Edmonton, Canada. Available online at https://doi.org/10.7939/ R3H98ZR60

Whitman, W.B., Coleman, D.C., Wiebe, W.J., Smith, D.C., and D'Hondt, S. (1998) Prokaryotes: the unseen majority. Proc Natl Acad Sci USA 95:6578-6583.

Wiens, R.C., Maurice, S., Barraclough, B., Saccoccio, M., Barkley, W.C., Bell, J.F., Bender, S., Bernardin, J., Blaney, D., Blank, J., Bouyé, M., Bridges, N., Bultman, N., Caïs, P., Clanton, R.C., Clark, B., Clegg, S., Cousin, A., Cremers, D., Cros, A., Deflores, L., Delapp, D., Dingler, R., D’Uston, C., Darby Dyar, M., Elliott, T., Enemark, D., Fabre, C., Flores, M., Forni, O., Gasnault, O., Hale, T., Hays, C., Herkenhoff, K., Kan, E., Kirkland, L., Kouach, D., Landis, D., Langevin, Y., Lanza, N., Larocca, F., Lasue, J., Latino, J., Limonadi, D., Lindensmith, C., Little, C., Mangold, N., Manhes, G., Mauchien, P., McKay, C., Miller, E., Mooney, J., Morris, R.V., Morrison, L., Nelson, T., Newsom, H., Ollila, A., Ott, M., Pares, L., Perez, R., Poitrasson, F., Provost, C., Reiter, J.W., Roberts, T., Romero, F., Sautter, V., Salazar, S., Simmonds, J.J., Stiglich, R., Storms, S., Striebig, N., Thocaven, J.J., Trujillo, T., Ulibarri, M., Vaniman, D., Warner, N., Waterbury, R., Whitaker, R., Witt, J., and Wong-Swanson, B. (2012) The ChemCam instrument suite on the Mars Science Laboratory (MSL) rover: body unit and combined system tests. Space Sci Rev 170:167-227.

Willerslev, E., Hansen, A.J., and Poinar, H.N. (2004) Isolation of nucleic acids and cultures from fossil ice and permafrost. Trends Ecol Evol 19:141-147.

Williams, A.J., Muñoz, C., Craft, K., Milan, M., Johnson, S.S., Thompson, P., and Hu, D. (2019) Martian hot spring 
deposits as a depot for biosignatures (and extant life?) [abstract 5016]. In Mars Extant Life: What's Next? Conference Abstracts, Lunar and Planetary Institute, Houston. Available online at https://www.hou.usra.edu/meetings/ lifeonmars2019/pdf/5016.pdf

Williams, J.M., Nagle-McNaughton, T.P., Scuderi, L.A., Newsom, H.E., and Gallegos, Z.E. (2019) Remote sensing techniques that aid in the identification of locations with high biosignature preservation potential [abstract 5021]. In Mars Extant Life: What's Next? Conference Abstracts, Lunar and Planetary Institute, Houston. Available online at https:// www.hou.usra.edu/meetings/lifeonmars2019/pdf/5021.pdf

Wong, U.Y. and Whittaker, W.L. (2015) Robotic exploration and science in pits and caves: results from three years and counting of analog field experimentation. In $2^{\text {nd }}$ International Planetary Caves Conference. Available online at https://ui.adsabs.harvard.edu/abs/2015LPICo1883.9031W/ abstract

Wray, J.J., Milliken, R.E., Dundas, C.M., Swayze, G.A., AndrewsHanna, J.C., Baldridge, A.M., Chojnacki, M., Bishop, J.L., Ehlmann, B.L., Murchie, S.L., Clark, R.N., Seelos, F.P., Tornabene, L.L., and Squyres, S.W. (2011) Columbus Crater and other possible groundwater-fed paleolakes of Terra Sirenum, Mars. J Geophys Res Planets 116, doi: 10.1029/2010JE003694.

Yeager, C.M., Lanza, N.L., Marti-Arbona, R., Teshima, M., Lingappa, U.F., and Fischer, W.W. (2019) Terrestrial rock varnish: implications for biosignatures on Mars [abstract 5060]. In Mars Extant Life: What's Next? Conference Abstracts, Lunar and Planetary Institute, Houston. Available online at https://www.hou.usra.edu/meetings/lifeonmars2019/ pdf/5060.pdf

Zacny, K., Wang, A., Hedlund, M., Paulsen, G., Mellerowicz, B., Quinn, J., Yaggi, B., Hyman, C., and Smith, J. (2016) Resource prospector drill performance during the integrated payload tests. In 2016 IEEE Aerospace Conference, IEEE, Piscataway, NJ, doi:10.1109/AERO.2016.7500535.

Zent, A. (2008) A historical search for habitable ice at the Phoenix landing site. Icarus 196:385-408.

Zent, A.P. and McKay, C.P. (1994) The chemical reactivity of the martian soil and implications for future missions. Icarus 108:146-157.
Zorzano, M.-P., Mateo-Martí, E., Prieto-Ballesteros, O., Osuna, S., and Renno, N. (2009) Stability of liquid saline water on present day Mars. Geophys Res Lett 36, doi:10.1029/ 2009GL040315.

Address correspondence to:

Brandi Carrier

NASA Jet Propulsion Laboratory 4800 Oak Grove Drive

MS 321-630

Pasadena, CA 91109-8001

E-mail: bcarrier@jpl.nasa.gov

David Beaty

NASA Jet Propulsion Laboratory 4800 Oak Grove Drive

MS 321-630

Pasadena, CA 91109-8001

E-mail: dwbeaty@jpl.nasa.gov

Michael Meyer

NASA Mars Exploration Program

NASA Headquarters

Washington, DC 20546

E-mail: michael.a.meyer@nasa.gov

Submitted 27 January 2020

Accepted 24 March 2020

\begin{tabular}{rl|} 
Abbreviations Used \\
FTT $=$ Fischer-Tropsch type \\
GC-MS $=$ gas chromatography-mass spectrometry \\
JPL $=$ Jet Propulsion Laboratory \\
MS/MS $=$ tandem mass spectrometry \\
TEM $=$ transient electromagnetic \\
TRL $=$ Technology Readiness Level \\
VALKYRIE $=$ Volatiles And Life: KeY Reconnaissance \\
and In-situ Exploration
\end{tabular}

